LOBBY: ESTUDO DE DIREITO COMPARADO E NECESSIDADE DE REGULAMENTAÇÃO DO INSTITUTO NO ORDENAMENTO JURÍDICO BRASILEIRO

\author{
Tese de Doutorado
}

Orientador: Professor Titular Miguel Reale Júnior

UNIVERSIDADE DE SÃO PAULO

FACULDADE DE DIREITO

São Paulo-SP

2019 


\title{
LOBBY: ESTUDO DE DIREITO COMPARADO E NECESSIDADE DE REGULAMENTAÇÃO DO INSTITUTO NO ORDENAMENTO JURÍDICO BRASILEIRO
}

\begin{abstract}
Tese apresentada à Banca Examinadora do Programa de Pós-Graduação em Direito, da Faculdade de Direito da Universidade de São Paulo, como exigência parcial para obtenção do título de Doutor em Direito, na área de concentração Direito Penal, Medicina Forense e Criminologia, sob a orientação do Professor Titular Miguel Reale Júnior.
\end{abstract}

UNIVERSIDADE DE SÃO PAULO

FACULDADE DE DIREITO

São Paulo-SP

2019 
Serviço de Biblioteca e Documentação Faculdade de Direito da Universidade de São Paulo

Gontijo, Conrado Almeida Corrêa

Lobby: estudo de direito comparado e necessidade de regulamentação do instituto no ordenamento jurídico brasileiro / Conrado Almeida Corrêa Gontijo. -- São Paulo: USP / Faculdade de Direito, 2019.

$315 f$.

Orientador: Professor Titular Miguel Reale Júnior.

Tese (Doutorado), Universidade de São Paulo, USP, Programa de PósGraduação em Direito - área de concentração - Direito Penal, Medicina Forense e Criminologia, 2019.

1. Direito Penal. 2. Lobby. 3. Democracia. 4. Regulamentação. I. Reale Júnior, Miguel. II. Título. 


\section{FOLHA DE APROVAÇÃo}

Nome: Conrado Almeida Corrêa Gontijo

Título: Lobby: estudo de direito comparado e necessidade de regulamentação do instituto no ordenamento jurídico brasileiro

Natureza: Tese de Doutorado

Instituição: Faculdade de Direito da Universidade de São Paulo

Orientador: Professor Titular Miguel Reale Júnior

Área de Concentração: Direito Penal, Medicina Forense e Criminologia

Data da Banca:

\section{Banca Examinadora}

Professor Titular Miguel Reale Júnior (Orientador) 
Aos meus pais, Geraldo e Claudia, à Victória e à Maria Carolina. 


\section{AGRADECIMENTOS}

Iniciei os agradecimentos da minha dissertação de mestrado expondo a absoluta importância que o Professor Miguel Reale Júnior tem em minha formação. Destaquei que ele e os seus ensinamentos foram determinantes na definição dos caminhos que trilhei no passado e eram fonte de inspiração e exemplo para os passos que viria a dar no futuro.

Sobre o passado, enfatizei as lições com ele aprendidas desde o ano de 2007, como aluno de graduação da Faculdade de Direito do Largo de São Francisco, a oportunidade que me ofereceu de trabalhar sob sua supervisão em projeto de iniciação científica, a vivência intensa da advocacia criminal em seu escritório, situações que conduziram, após muito esforço e estudo, à minha admissão como seu orientando no programa de mestrado da USP, para tratar do tema da corrupção no setor privado.

À época, o Professor Miguel Reale Júnior havia anunciado a sua aposentadoria da docência e, por isso, havia decidido não mais admitir orientandos nos programas de pósgraduação da Faculdade de Direito. Integrei, assim, o último grupo de alunos orientados por ele, o que representou para mim um destacado privilégio.

Passados mais de quatro anos desde que o Professor Miguel Reale Júnior havia decidido não mais admitir orientandos de mestrado e doutorado, a Professora Marina Coelho Araújo, pessoa também fundamental em minha formação, durante a realização do meu exame de conclusão do mestrado, afirmou acreditar que ele pudesse abrir uma única vaga - efetivamente a última — para algum candidato ao programa de pós-graduação.

A partir de então, fui buscar um tema que pudesse convencê-lo a me escolher nessa oportunidade única e, então, apreensivo e sem grandes pretensões, elaborei projeto de estudo para tratar do fenômeno do lobby, que foi por ele aprovado: mais uma vez, o Professor Miguel Reale Júnior me concedeu o privilégio de ser por ele orientado, em razão do que, mais uma vez, inicio por ele os agradecimentos pela realização da tese.

Ao longo de mais de dez anos de convivência, recebi do Professor Miguel Reale Júnior diversos votos de confiança, pelos quais a ele sou absoluta e eternamente grato.

Às queridas professoras Helena Regina Lobo da Costa e Marina Coelho Araújo, agradeço pelas preciosas considerações feitas no exame de qualificação.

Aos meus pais, Geraldo e Cláudia, e à Victória, minha irmã, que, com infinito amor e absoluta dedicação, estiveram ao meu lado em cada momento da vida, dando-me força para buscar a concretização dos meus sonhos: o amor de vocês é essencial para minha caminhada e para tolerar a distância e a saudade. 
À Maria Carolina, que dá leveza à minha vida e sem a qual a conclusão deste trabalho, por uma série infindável de motivos, não teria sido possível.

A todos os amigos que tenho, principalmente àqueles que estão sempre próximos de mim, contribuindo para dar ainda mais sentido às experiências da minha vida, e às diversas pessoas que ajudaram no desenvolvimento da tese. Em especial, destaco Aldo Romani, Amanda do Valle, Andrey Borges Mendonça, Antônio Carlos Tovo Loureiro, Antônio Carlos de Almeida Castro, Antônio Sérgio de Moraes Pitombo, Bruno Maglioni, Carlos Eduardo Nakaharada, Carolina Sayegh, Daniel Demidio, Daniel Zaclis, Dannyele Galvão, Diego Polachini, Diogo Cornacchioni, Felipe Andreu Silva, Fernanda Regina Vilares, Fernando Bosso, Filipe Tavares, Gabriel Pereira, Gabriel Prudente, Gustavo Turbiani, Gustavo Vaughn, Helena Regina Lobo da Costa, Heloisa Estellita, Igor Mauler Santiago, João Francisco Moreira Viegas, Judith Martins-Costa, Laís e Larissa Siqueira, Leonardo Magalhães Avelar, Lucas Marujo, Lumena Castro Furtado, Marcelo Perez, Marcelo Turbay, Maria Célia Gontijo, Maria Cristina Moreira Viegas, Maria de Lourdes Gontijo, Maria Josefina Fuentes, Mariana Tranchesi Ortiz, Miguel Pereira Neto, Natália Veiga, Nicole Ellovitch, Pedro Machado de Almeida Castro, Renata Benitez, Ricardo Sidi, Rodolfo Ribeiro, Odair Furtado... Há muitos outros e, por esse motivo, inviável declinar todos os seus nomes. De qualquer maneira, muito obrigado: vocês são fundamentais. 
GONTIJO, Conrado Almeida Corrêa. Lobby: estudo de direito comparado e necessidade de regulamentação do instituto no ordenamento jurídico brasileiro. 2019. 315f. Tese (Doutorado). Faculdade de Direito da Universidade de São Paulo, São Paulo, 2019.

\section{RESUMO}

A presente tese versa sobre o instituto do lobby e sobre a necessidade de que ele seja objeto de regulamentação na ordem jurídica brasileira. Inicia-se o trabalho acadêmico com a análise das características elementares do lobby, sua história, a expansão de sua relevância nas últimas décadas, sua importância para a efetivação de importantes valores democráticos, os mecanismos de atuação dos lobistas e os problemas que eles podem criar para a administração pública. Assentadas as premissas basilares do instituto, passa-se à demonstração de que é essencial, para que se assegure a moralidade, a probidade e a transparência nas inevitáveis relações entre os lobistas e os agentes públicos, a criação de parâmetros normativos para a sua realização, medida que tem sido adotada em diversas nações mundo afora. Em seguida, para que seja possível identificar os mais adequados instrumentos de regulamentação do lobby, é examinado, sob o viés do direito comparado, o tratamento jurídico a ele dispensado nos Estados Unidos, no Canadá, no Reino Unido, no Chile e na União Europeia. Considerada a experiência vivenciada nas nações referidas, fazse incursão na realidade política e jurídica brasileira, com o exame dos preceitos constitucionais que albergam a atuação dos lobistas e daqueles que exigem seja ela realizada com ampla transparência; dos projetos legislativos que objetivam regulamentar a atuação dos lobistas e das ferramentas de controle que, em nossa visão, devem ser contempladas no Brasil. Ademais, observando os princípios fundamentais da ultima ratio, da subsidiariedade, da fragmentariedade e da legalidade, examina-se a relação e a distinção entre o lobby e os tipos penais de corrupção, prevaricação, advocacia administrativa, tráfico de influência e exploração de prestígio e apresentam-se propostas de reformulação legislativa, com vistas à promoção da racionalidade do sistema jurídico-penal nacional. Por fim, propõe-se a tipificação penal dos comportamentos praticados em contexto de lobby que, em nosso entender, devam ser sancionados na ordem jurídica brasileira.

Palavras-chave: Lobby. Democracia. Regulamentação. Direito penal 
GONTIJO, Conrado Almeida Corrêa. Lobby: the need for the institution to be subject to regulation in the Brazilian legal system. 2019. 315p. PhD Thesis, Faculty of Law, University of São Paulo, São Paulo, 2019.

\begin{abstract}
This thesis deals with the lobby institution and the need for it to be subjected to regulation in the Brazilian legal system. The thesis starts with the analysis of the elementary features of the lobby institution, its history, the expansion of its relevance in the past decades, its importance for the accomplishment of significant democratic values, the lobbyists' action mechanisms and the problems that they can create for the Public Administration. Once the basic premises of the institution have been established, the thesis goes on to demonstrate that it is essential to ensure morality, probity and transparency in the inevitable relations between lobbyists and public agents, the creation of normative parameters for their realization, a measure that has been adopted in many nations around the world. Then, in order to identify the most appropriate lobbying regulation instruments, it is examined, under the perspective of comparative law, the legal treatment provided in the United States, Canada, the United Kingdom, Chile and the European Union. Considering the experience in those nations, the thesis begins an incursion into the political and legal Brazilian reality, through the analysis of the constitutional commands that support lobbyists' actions as well as those who demand that they be carried out with ample transparency; of legislative projects that aim to regulate the lobbyists' actions and control apparatus that, in our view, should be contemplated in Brazil. In addition, observing the fundamental principles of ultima ratio, subsidiarity, fragmentarity and legality, the relationship and distinction between the lobby institution and the criminalized conducts against Public Administration are examined. It is also proposed legislative reforms aiming to promote the rationality of the national criminal law system. Lastly, it is proposed to criminalize behaviors practiced in the lobbying context that, in our understanding, should be sanctioned in the Brazilian legal system.
\end{abstract}

Key Words: Lobby. Democracy. Regulamentation. Criminal law 
GONTIJO, Conrado Almeida Corrêa. Lobby: della necessità de che sia oggetto di regolamentazione nell'ambito dell'ordinamento giuridico brasiliano. 2019. 315p. Tesi (Dottorato). Facoltà di Diritto del’Università di São Paulo, 2019.

\section{RIASSUNTO}

Questa tesi tratta dell'istituto del lobby e della necessità che esso sia oggetto di regolamentazione nell'ambito dell'ordinamento giuridico brasiliano. All'inizio si effettua un'analisi delle caratteristiche elementari del lobby, della sua storia, dell'aumento della sua rilevanza negli ultimi decenni, della sua importanza per la realizzazione di valori democratici, dei meccanismi di azione dei lobbisti e dei problemi che essi possono creare alla pubblica amministrazione. Poste le premesse fondamentali dell'istituto, si passa alla dimostrazione che è essenziale per garantire la moralità, la probità e la trasparenza nei rapporti inevitabili fra lobbisti e agenti pubblici la creazione di parametri normativi per la realizzazione di essi, misura che è stata adottata da diversi paesi del mondo.

In seguito, allo scopo di identificare gli strumenti più adatti alla regolamentazione del lobby, è esaminato, dal punto di vista del diritto comparato, l'approccio ad esso dedicato negli Stati Uniti d'America, in Inghilterra, in Cile e nell'Unione Europea. Con base nell'esperienza osservata nei paesi citati, si concentra poi l'attenzione sulla realtà politica e giuridica brasiliana per prendere in esame i precetti costituzionali che guidano l'azione dei lobbisti e di coloro che esigono che essa sia messa in atto con ampia trasparenza e dei progetti legislativi destinati a regolamentare l'azione dei lobbisti, come pure gli strumenti di controllo che, secondo noi, devono essere adottati in Brasile. Oltre a ciò, seguendo i principi fondamentali della ultima ratio, della sussidiarietà, della frammentazione e della legalità, si analizzano il rapporto e la differenza fra il lobby e i diversi tipi di delitti contro la pubblica amministrazzione e si presentano proposte di riformulazione legislativa in funzione della razionalizzazione del sistema giuridico-penale nazionale. Infine, si propone la tipizzazione penale dei comportamenti tenuti nel contesto dei lobby che, secondo noi, devono essere sanzionati nell'ambito del sistema giuridico brasiliano.

Parole chiave: Lobby. Democrazia. Regolamentazione. Diritto penale. 


\section{SUMÁRIO}

\section{O LOBBY: TEMAS ESSENCIAIS PARA A COMPREENSÃO DO INSTITUTO}

1.1. O lobby e considerações a partir de uma perspectiva histórica

1.2. A expansão da prática do lobby nas últimas décadas e a sua presença nos diversos espaços da administração pública estatal

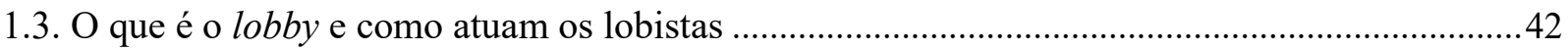

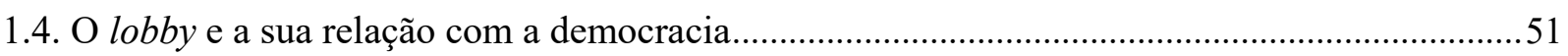

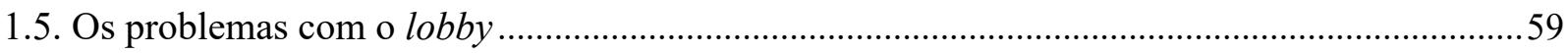

1.6. A regulamentação do lobby como mecanismo de proteção da transparência e da moralidade no âmbito da administração pública

1.7. As ferramentas de controle utilizadas na regulamentação do lobby.....

\section{A REGULAMENTAÇÃO DO LOBBY NO DIREITO COMPARADO: MODELOS} E INSTRUMENTOS DE CONTROLE

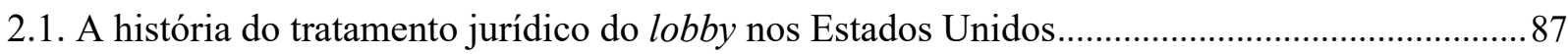

2.1.1. O Lobbying Disclosure Act de 1995: história e conteúdo normativo...................................96

2.1.2. O Honest Leadership and Open Government Act de 2007: história e conteúdo

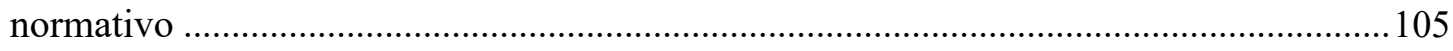

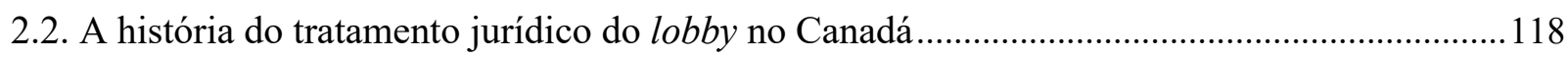

2.2.1. O Lobbyist Registration Act de 1989: história e conteúdo normativo ................................ 123

2.2.2. O Lobbying Act de 2008: história e conteúdo normativo.................................................. 131

2.3. A história do tratamento jurídico do lobby no Reino Unido .......................................................... 140

2.3.1. O Transparency of Lobbying, Non-Party Campaign and Trade Union Administration Act de 2014: história e conteúdo normativo............................................. 147

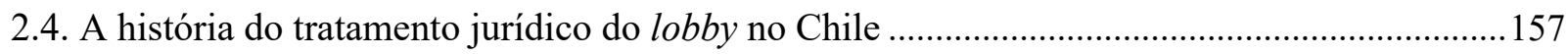

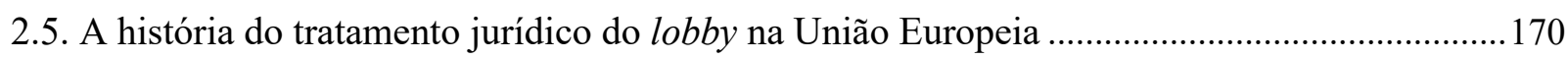

2.5.1. O tratamento jurídico do lobby no Parlamento Europeu..................................................... 173

2.5.2. O tratamento jurídico do lobby na Comissão Europeia........................................................ 177

2.5.3. A iniciativa conjunta da Comissão Europeia e do Parlamento Europeu para o tratamento jurídico do lobby (o Registro de Transparência)................................................ 184

\section{ASPECTOS ESSENCIAIS PARA A REGULAMENTAÇÃO DO LOBBY NO ORDENAMENTO JURÍDICO BRASILEIRO}

3.1. Panorama da regulamentação do lobby no Brasil

3.2. A análise do direito penal brasileiro, dos tipos penais erigidos para a proteção da administração pública e da sua relação com o lobby 


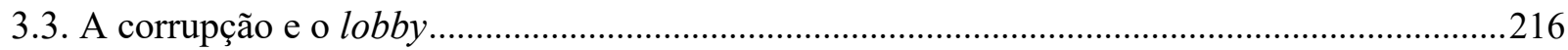

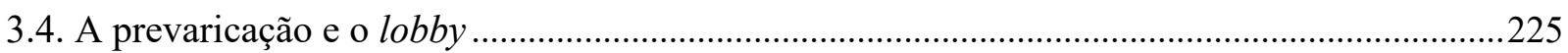

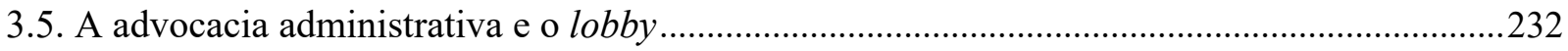

3.6. O tráfico de influência, a exploração de prestígio e o lobby .......................................................240

3.6.1. Considerações sobre a aparente relação entre as condutas que caracterizam os crimes de tráfico de influência e exploração de prestígio e o lobby

3.6.2. Análise crítica dos crimes de tráfico de influência e exploração de prestígio à luz

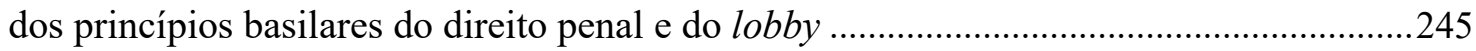

3.6.3. Como tratar o tráfico de influência real no âmbito da administração pública ...................254

3.7. A tipificação das condutas do lobista cadastrado que negocie influência para estimular a prática de atos ilegais por funcionários públicos ou pessoas a eles juridicamente

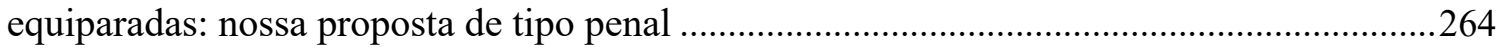

CONCLUSÕES

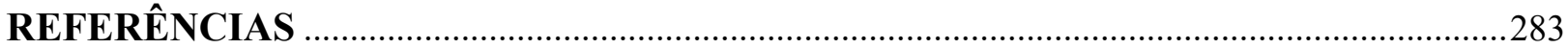




\section{INTRODUÇÃO}

Basta uma superficial pesquisa nos domínios eletrônicos dos mais importantes veículos de jornalismo do país para constatar que a prática do lobby é indissociável do cotidiano dos órgãos da administração pública nacional. Constata-se, outrossim, que, embora sejam inúmeras as veiculações que revelam ser o instituto mencionado essencial para a defesa de interesses legítimos junto aos agentes do Estado ${ }^{1}$, na grande parte dos casos, ele é tratado como se assemelhado fosse à corrupção ${ }^{2}$.

Tais constatações não são particularidades do Brasil. Consoante exporemos na presente tese, a atuação de agentes com o propósito de influenciar os processos decisórios no âmbito estatal é imemorial, onipresente e elementar para a acomodação dos diversos interesses que coexistem em agrupamentos humanos, havendo registros históricos, já nas civilizações antigas, da recorrência desse tipo de prática ${ }^{3}$.

Em regimes políticos de perfil democrático, o lobby ganha contornos ainda mais importantes, por representar uma das mais claras manifestações do direito de petição, o qual tem sido expressamente contemplado em inúmeras cartas constitucionais mundo

\footnotetext{
${ }^{1}$ Reportagens publicadas no ano de 2018, apenas para exemplificar, expõem a importância da atuação dos lobistas para a promoção dos interesses (i) dos servidores públicos, no tocante à reforma da previdência (NÓBREGA, Mailson da. O lobby dos servidores contra a reforma da Previdência. Blog Mailson da Nóbrega, 18 dez. 2017. Disponível em: <https://veja.abril.com.br/blog/mailson-da-nobrega/o-lobby-dosservidores-contra-a-reforma-da-previdencia $>$. Acesso em: 15 jan. 2018), (ii) dos empresários do agronegócio (PEREIRA, Pablo; ALMEIDA, Neila; OLIVEIRA, Paulo. Agronegócio tem a bancada mais bem organizada do Congresso. UOL Últimas Notícias (Estadão Conteúdo), São Paulo, 29 jul. 2018. Disponível em: <https://noticias.uol.com.br/ultimas-noticias/agencia-estado/2018/07/29/agronegocio-tema-bancada-mais-bem-organizada-do-congresso.htm $>$. Acesso em: 16 set. 2018), (iii) dos integrantes Poder Judiciário, por aumento de proventos (JUDICIÁRIO faz lobby e pressiona governo a aumentar salários da magistratura. Folha de S. Paulo, São Paulo, painel, 29 jun. 2018. Disponível em: $<$ https://painel.blogfolha.uol.com.br/2018/06/29/judiciario-faz-lobby-e-pressiona-governo-a-aumentarsalarios-da-magistratura/>. Acesso em: 15 ago. 2018), e (iv) dos notários contra medidas que não beneficiam a atuação dos cartórios (CARNEIRO, Mariana. Cartórios fazem lobby contra cadastro positivo. Folha de $S$. Paulo, São Paulo, abr. 2018. Disponível em: < https://www1.folha.uol.com.br/mercado/2018/04/cartoriosfazem-lobby-contra-cadastro-positivo.shtml>. Acesso em: 02 set. 2018).

${ }^{2} \mathrm{~A}$ revelar a associação que se faz entre lobby e corrupção, veja-se: (i) TAVARES, Bruno; LEITE, Isabela. Polícia Federal faz operação contra desvio recursos da União para merenda em 3 Estados e no DF. G1, 09 maio 2018. Disponível em: <https:/g1.globo.com/sp/sao-paulo/noticia/policia-federal-faz-operacao-contradesvio-de-dinheiro-publico.ghtml>; (ii) TEIXEIRA, Luiz Fernando; MACEDO, Fausto. Lobista do MDB pede habeas. Estadão, 16 abr. 2018. Disponível em: <https://politica.estadao.com.br/blogs/faustomacedo/lobista-do-mdb-pede-habeas//>. Acesso em: 10 out. 2018; (iii) VIEIRA, André Guilherme; DI CUNTO, Raphael. PF realiza operação contra fraude milionária em registros sindicais. Valor Econômico, 30 maio 2018. Disponível em: <https:/www.valor.com.br/politica/5559437/pf-realiza-operacao-contrafraude-milionaria-em-registros-sindicais>. Acesso em 15 jun. 2018.

${ }^{3}$ Milbrath esclarece que a atuação dos lobistas preexiste, inclusive, à própria definição dos contornos do poder do Estado (MILBRATH, Lester W. The Washington lobbyists. Chicago: Rand McNally \& Company, 1963. p. 12 e 179).
} 
afora, e por criar vias de acesso da sociedade àqueles aos quais se conferem competências e atribuições para em nome dela delinear a atuação do Estado. Sob esse prisma, o lobby é uma ferramenta que, assim como o voto, permite ao cidadão adotar medidas com o fim de interferir nas decisões públicas e, assim, satisfazer os seus interesses.

Além disso, com a incursão do poder normativo estatal em novos espaços sociais e econômicos, nos quais os tomadores de decisão são confrontados com uma complexa teia de interesses, as informações técnicas que podem ser produzidas pelos lobistas propiciam seja a atuação dos órgãos públicos mais eficaz, porque suportada por discussões amplas, nas quais consideradas as perspectivas de todos os atores nela implicados.

Entretanto, é igualmente difundida em todas as nações do globo a percepção de que os lobistas põem em risco os valores da probidade, da impessoalidade e da moralidade reitores da administração pública - e funcionam como verdadeiros agentes promotores da corrupção. Sobre essa temática, serão abordados na presente tese inúmeros estudos científicos e dados estatísticos que apontam que o instituto sub examinen, malgrado inerente à noção de democracia, é notado pela sociedade como instrumento de favorecimento de classes privilegiadas, de forma oculta e ilegal.

Registre-se que a percepção social que confunde o instituto objeto do estudo monográfico presente com práticas corruptas decorre de circunstâncias que, ao menos parcialmente, a justificam. Com efeito, no curso da história e ainda hodiernamente, divulgam-se episódios em que os lobistas, para alcançar êxito em suas iniciativas persuasórias, oferecem ou concedem vantagens indevidas a membros do corpo estatal, de modo a estimulá-los a proferir decisões que lhes sejam favoráveis.

Não se pode ignorar, além disso, que nem todos os atores sociais dispõem de meios materiais para promover, por via da contratação de lobistas, os seus interesses junto aos órgãos da administração pública. Em situações que tais, o lobby continua sendo um caminho de diálogo entre a sociedade e os agentes do Estado, todavia, um caminho que apenas uma pequena parte dela tem condições de trilhar, situação que não se coaduna com os preceitos basilares que devem imperar em regimes democráticos.

Nota-se, destarte, que o lobby é instituto complexo, de inequívoca importância para a democracia, mas que, a depender da forma como praticado, pode minar os atributos fundamentais que a caracterizam. Por esse motivo, para que se alcance um equilíbrio na proteção das liberdades individuais e do direito de petição, por um lado, e da moralidade, 
probidade e transparência na atuação do Estado, por outro, revela-se imperioso o desenvolvimento de disciplina jurídica que recaia sobre o instituto, medida que tem sido adotada por cada vez mais países. É com essa conclusão que encerramos o capítulo primeiro deste trabalho científico.

Em suma, o lobby é necessário e deve ser realizado de forma explícita, de maneira que a sociedade conheça os fatores que influenciam os processos de decisão no âmbito da administração pública, o que não se alcança sem regulamentação. Necessária, pois, a adoção de medidas que estimulem a atuação ética dos lobistas, garantam que ela se dê de forma transparente, sem abusos nem comportamentos ilícitos.

Colhe-se das Novas Medidas Contra a Corrupção, propostas pela Transparência Internacional em conjunto com a Fundação Getúlio Vargas (FGV), que "a falta de regulamentação" do lobby "gera graves problemas, especialmente considerando-se os desafios éticos dessa interação". Assim, "propõe-se a regulamentação do lobby para conferir a essa atividade a transparência e a probidade necessárias e garantir a lisura das interações" entre o setor público e o setor privado, para o que é essencial eleger, com cuidado, as ferramentas a serem empregadas com esse desiderato.

Assentadas as premissas de que o lobby é essencial ao funcionamento de qualquer regime de cariz democrático, por representar importante manifestação do direito de petição e de expressão do pensamento, mas deve ser regulamentado, para que sejam transparentes as relações entre agentes do setor público e agentes do setor privado, analisaremos no capítulo segundo da tese a história do tratamento jurídico dispensado ao instituto em diversos sistemas positivos.

Iniciaremos a análise da disciplina do lobby no direito comparado com o exame aprofundado da sistemática vigente nos Estados Unidos, nação que primeiro dedicou esforços para monitorar a atuação dos lobistas. Não obstante se prevejam no Direito norteamericano, desde a primeira metade do século XX, dispositivos normativos obrigatórios que visam a promover maior clareza nas articulações entre os profissionais do lobby e os funcionários estatais, bem como a sancionar, inclusive criminalmente, as situações ilegais que possam delas defluir, constata-se serem muitas as dificuldades para imprimir efetividade a tais dispositivos normativos.

Essa situação, cumpre registrar, encontra paralelo em vários outros países. Assim, com a finalidade de desenvolver conhecimento amplo sobre as diversas variáveis 
existentes nos regramentos que buscam mundo afora incidir sobre o instituto do lobby, debruçaremos nossa atenção, também no capítulo segundo, às iniciativas implementadas no Canadá, no Reino Unido, no Chile e na União Europeia.

Será possível perceber, a partir desse estudo, que há inequívoca tendência mundial à criação de preceitos que recaiam sobre a atuação dos lobistas, mas enorme dificuldade na escolha das ferramentas que devem ser utilizadas para que ela seja eficazmente disciplinada. Enquanto alguns ordenamentos apenas exigem dos profissionais dedicados ao lobby que se identifiquem junto aos órgãos públicos competentes, outros exigem também que indiquem os seus clientes, os interesses que têm no encaminhamento das discussões havidas no plano da administração pública, quais os projetos legislativos que pretendem influenciar, os funcionários públicos a quem direcionam suas iniciativas de convencimento, o tempo que gastam, quanto recebem e quanto despendem em razão dos serviços prestados.

Alguns modelos normativos concretos, além de exigirem do lobista que revele aos órgãos públicos inúmeras informações sobre as atividades que realiza, para que se dê ao Estado e à sociedade a possibilidade de conhecer as relações que o vinculam aos agentes públicos, fazem algumas proibições expressas. Nos Estados Unidos, no Canadá e no Reino Unido, por exemplo, veda-se a concessão de presentes, o pagamento de viagens e ingressos para a participação em eventos, havendo, ainda, rígido controle dos aportes financeiros feitos pelos lobistas e seus clientes em campanhas político-eleitorais.

A análise de direito comparado também deixará evidenciado que diversas são as respostas estatais nos casos em que os lobistas deixam de cumprir as normas erigidas para balizar a sua atuação, seja por omitirem dos órgãos públicos informações, seja por descumprirem obrigações negativas - proibições - a que estão sujeitos.

Com efeito, variadas são as modalidades de sanção previstas nos sistemas regulatórios estudados, podendo ser citadas, dentre as de natureza administrativa, a suspensão do lobista do exercício de suas atividades, o cancelamento de credenciais de acesso a prédios públicos, a divulgação em mídias eletrônicas de informações sobre as condutas de lobby ilegais e a imposição de multas de cunho econômico.

Tais medidas sancionatórias, não raro, dividem o espaço com a imposição de penas corporais. Nos Estados Unidos e no Reino Unido, o lobista pode sofrer punições de índole 
criminal, se dolosamente omitir informações relacionadas às suas iniciativas de persuasão junto à administração pública.

Todas essas medidas, sejam as de natureza administrativa, sejam as de índole jurídico-penal, são erigidas nos países analisados com o fím de pôr em harmonia a necessidade democrática de que haja vias de acesso aos agentes públicos e transparência na interação entre estes e os lobistas.

Todavia, da nossa perspectiva, dadas as limitações ao ius puniendi estatal, decorrentes dos postulados fundamentais da ultima ratio, da subsidiariedade e da fragmentariedade, embora primordial disciplinar o lobby, não se justifica a utilização do direito penal para, tão somente, reforçar as exigências administrativas à atuação dos lobistas. Consoante exporemos no texto elaborado, julgamos devam ser reservadas ao direito penal apenas hipóteses de especial gravidade, nas quais a atuação dos lobistas efetivamente tenha o condão de afetar o bem jurídico administração pública.

No Brasil, assim como acontece no estrangeiro, é crescente a atenção dispensada ao fenômeno do lobby. Não obstante induvidoso que a sua prática esteja albergada pela Constituição Federal, são cada vez mais frequentes as discussões sobre a necessidade de definição de parâmetros claros para a atuação dos lobistas. Para tratar dessas questões, reservamos o capítulo terceiro da tese.

Com efeito, a análise da dinâmica política da nação deixa evidenciado que a atuação dos lobistas é intensa junto aos órgãos da administração pública, situação que motivou, ainda no ano de 1986, por iniciativa do Senador Marco Maciel, a criação do primeiro projeto de lei que mirava disciplinar o instituto. Mais recentemente, em fevereiro de 2018, o Ministério do Trabalho inseriu a prática do lobby na Classificação Brasileira de Ocupações", que tem "por finalidade a identificação das ocupações no mercado de trabalho", e está em discussão no Congresso Nacional, após aprovação pela Comissão de Constituição e Justiça, o Projeto de Lei n ${ }^{\circ} 1.202 / 2007^{5}$.

\footnotetext{
${ }^{4}$ MINISTÉRIO DO TRABALHO E EMPREGO. Classificação Brasileira de Ocupações: CBO - 2010. 3. ed. Brasília-DF: MTE, SPPE, 2010. Disponível em: <http://www.cofen.gov.br/wpcontent/uploads/2015/12/CLASSIFICA $\%$ C3\%87\%C3\%83O-BRASILEIRA-DEOCUPA\%C3\%87\%C3\%95ES-MEC.pdf $>$. Acesso em: 15 mar. 2017.

${ }^{5}$ BRASIL. Câmara dos Deputados. PL 1202/2007. Disciplina a atividade de lobby e a atuação dos grupos de pressão ou de interesse e assemelhados no âmbito dos órgãos e entidades da Administração Pública Federal, e dá outras providências. Autor: Carlos Zarattini - PT/SP. Apresentação: 30/05/2007. Disponível em: <http://www.camara.gov.br/proposicoesWeb/fichadetramitacao?idProposicao=353631>. Acesso em: 08 jul. 2017.
} 
Referido projeto legislativo, de autoria do Deputado Federal Carlos Zarattini, "disciplina a atividade de lobby e a atuação dos grupos de pressão ou de interesse e assemelhados no âmbito dos órgãos e entidades da Administração Pública". Na contramão da evolução que se observa no exterior, sugere a implementação de modelo voluntário de cadastramento dos lobistas, não prevê exigências relacionadas à divulgação das atividades por eles realizadas, não estipula sanções efetivas para a prática do lobby ilegal e não aprimora, em nenhuma medida, a transparência que deve imperar na interação entre agentes públicos e particulares.

Trata-se, a bem da verdade, considerada a realidade já experimentada no plano internacional, de proposta legislativa absolutamente inócua, que nenhum benefício trará ao país, na hipótese de aprovada pelo Congresso Nacional; ao contrário, criará a falsa ilusão de que a atuação dos lobistas é regulamentada na ordem jurídica nacional.

Releva mencionar, porque atesta a assertiva de que se tem discutido o lobby no Brasil, que sua regulamentação é prevista nas Novas Medidas Contra a Corrupção propostas pela Transparência Internacional e Fundação Getúlio Vargas (FGV). Consta do referido documento que "o lobby é uma forma legítima de atuação dos mais variados setores da sociedade - sindicatos, empresas, ONGs - junto ao poder público”, que a falta de regulamentação dessa atividade "gera graves problemas" e que é imperiosa a sua regulamentação, para conferir à atuação dos lobistas "a transparência e a probidade necessárias e garantir a lisura das interações desses atores com autoridades públicas”.

Nesse contexto, analisaremos os preceitos constitucionais que dão guarida à prática do lobby no Brasil, bem assim aqueles que deixam evidenciada a imprescindibilidade de que a relação entre os lobistas e os funcionários públicos seja regida pelos valores da transparência e da probidade, sendo necessário, para que se alcance verdadeiro equilíbrio democrático, a efetiva regulamentação do instituto.

Avaliaremos, desse modo, as medidas de natureza administrativa que poderão ser adotadas pelo legislador ordinário para mitigar os riscos decorrentes da interação entre agentes da esfera pública e da esfera particular. Em especial, salientaremos a necessidade, para que haja real monitoramento de tal interação, de que todos os lobistas sejam, obrigatoriamente, cadastrados junto ao Estado, de forma transparente; de que todos os seus representados e os interesses por eles defendidos sejam revelados em relatórios periódicos que deverão ser disponibilizados aos órgãos públicos competentes; de que todos os 
encontros com funcionários públicos para fins de lobby, bem assim os assuntos neles tratados, sejam descritos nos referidos relatórios etc.

Ademais, no que concerne às consequências jurídicas do descumprimento das exigências de transparência a serem impostas, demonstraremos ser imperiosa a previsão de sanções administrativas gradativas, por via das quais o Estado ofereça resposta adequada e proporcional às condutas ilegais nas atividades de lobby, com o fim de reprimi-las e de criar um ambiente que estimule a observância dos preceitos normativos mínimos previstos na legislação.

Faremos, ainda, minudente análise dos tipos penais existentes na ordem jurídica brasileira que possam incidir sobre a atuação ilegal dos lobistas, ficando exposta nesse tópico a tese central do presente trabalho. Verificaremos que o ius puniendi estatal deve incidir apenas nas situações em que, efetivamente, constatar-se, na prática de lobby, atos graves que afetem a administração pública. Contrario sensu, não deverão ser sancionados os lobistas que simplesmente deixarem de observar as obrigações administrativas eventualmente criadas para disciplinar o lobby.

Por fim, após examinarmos as figuras típicas da corrupção, da prevaricação, da advocacia administrativa, do tráfico de influência e da exploração de prestígio, com o objetivo de avaliar se, da forma como descritas pelo legislador ordinário, são compatíveis com o instituto do lobby e em que medida dele se distinguem, proporemos, de lege ferenda, a criação de tipo penal. Tal tipo penal terá como objetivo sancionar o lobista que se proponha a adotar medidas de convencimento para a obtenção de decisão pública ilegal, bem como os clientes o contratem para tal fim. 


\section{CONCLUSÕES ${ }^{6}$}

1.1. O lobby é fenômeno indissociável do cotidiano dos órgãos estatais. Em que pese o vocábulo atualmente empregado para designá-lo tenha passado a ser usado, segundo fontes históricas, a partir de meados do século XIX, as iniciativas orientadas a influir nas decisões dos agentes do poder público para a satisfação de interesses privados e para a satisfação de interesses do próprio Estado, podem ser observadas em estudos sobre o ambiente político da Grécia e Roma antigas, antes da assinatura da Magna Carta por João Sem-Terra etc.

1.2. O lobby apresenta-se como fenômeno global e diário, tendo se tornado cada vez mais importante para a composição dos inúmeros interesses existentes nas sociedades. Onde quer que existam pessoas convivendo em grupo, há interesses distintos a serem contemplados pelo Estado, e há lobby.

1.3. Nas últimas décadas, houve uma sensível ampliação do papel do Estado na definição de políticas que impactem significativamente os interesses sociais. Com efeito, passaram a ser objeto da atividade regulatória do Estado diversas áreas econômicas que, historicamente, eram disciplinadas por seus próprios atores. Antes irrelevantes, as decisões tomadas pelos administradores públicos passaram a ser fundamentais para o desenvolvimento de variados setores da vida social e econômica, o que motivou uma verdadeira corrida para a contratação de profissionais do lobby.

1.4. A quantidade de interesses em conflito sofreu enorme aumento com o incremento da complexidade social no pós-guerra, situação que tornou mais importante que os agentes buscassem o Estado para que seus interesses fossem atendidos.

1.5. Fala-se, em razão desses e de outros fatores, ter havido verdadeira explosão na quantidade de lobistas ativos em todos os países do mundo. Conglomerados econômicos, dentre os quais a Pfizer, Boeing, Airbus, Telefonica etc., inclusive, dispõem de grandes equipes internas que têm como única finalidade a prática do lobby junto a entidades estatais, supranacionais e internacionais.

1.6. Embora os atores sociais que mais recursos despendem com a atuação dos lobistas sejam os grandes conglomerados empresariais, também tentam influir nas decisões

\footnotetext{
${ }^{6} \mathrm{Na}$ numeração destas conclusões, o primeiro algarismo indica o capítulo do trabalho do qual extraída a afirmação, e, o seguinte, a sequência das conclusões de cada capítulo.
} 
estatais as associações comerciais, as associações profissionais, as entidades da sociedade civil organizada, os sindicatos de trabalhadores, as entidades de caridade, universidades, entidades religiosas e, até mesmo, órgãos do próprio Estado.

1.7. No que concerne ao lobby praticado pelos agentes estatais, que se convencionou denominar no estrangeiro de lobby institucional, estudos indicam que as mais poderosas e agressivas tentativas de influenciar as decisões governamentais, muitas vezes, surgem dentro do próprio governo.

1.8. Em suma: o lobby não é instrumento de tutela e promoção de interesses exclusivamente privados junto ao Estado. É, sim, ferramenta essencial para o equacionamento dos diversos interesses em conflito numa sociedade complexa como a atual, sendo indiferente quem sejam os titulares de tais interesses.

1.9. A prática do lobby não tem como objetivo influenciar apenas a atuação do Poder Legislativo federal. Ao contrário, e essa situação pode ser verificada em todos os países do mundo, a prática do lobby tem grande importância na conformação das decisões do Poder Executivo e do Poder Judiciário, tanto no plano local, quanto no estadual, e até mesmo nos planos internacional e supranacional.

1.10. Nos tempos atuais, a atuação dos lobistas é altamente técnica e extrapola a tradicional noção de que se resume a entabular contatos com agentes públicos para promover os interesses de seus representados. Para influenciar a opinião dos agentes do Estado nos processos decisórios que impactem os interesses que representam, os lobistas realizam pesquisas e estudos sobre temas estratégicos, monitoram ostensivamente as atividades dos órgãos públicos, contribuem com a elaboração de minutas de propostas legislativas, participam de comitês temáticos e audiências públicas, elaboram estudos técnicos sobre os temas que lhes sejam de interesse, buscam criar canais de interface entre os agentes do Estado e a sociedade para que esta os pressione a atender aos interesses de seus clientes, e, é evidente, realizam contatos pessoais com aqueles que possam contribuir para o sucesso do lobby.

1.11. A atividade do lobby, não obstante presente em todos os agrupamentos sociais, tem singular importância nos regimes democráticos por estar inserida no espectro de proteção dos direitos fundamentais de livre manifestação e de petição. Ademais, o intercâmbio de informações propiciado pela interação entre os lobistas e os agentes públicos favorece a qualidade da atuação do Estado, além de conferir maior legitimidade às 
suas escolhas, pois tomadas a partir da análise e discussões das quais participam os agentes sociais por elas impactados.

1.12. É fundamental destacar, nesse aspecto, ser amplamente difundida a ideia de que a prática do lobby propicia a produção de melhores decisões no plano estatal, situação que revela não apenas que o instituto é legítimo, mas também importante para o aprimoramento da atuação do poder público.

1.13. As vantagens geradas pela prática do lobby, em especial, nos regimes democráticos, não são unidirecionais. Ao contrário, a interação entre os lobistas e os agentes do setor público gera benefícios recíprocos e dá origem a uma verdadeira relação de interdependência (exchange relation): enquanto os lobistas precisam estimular processos decisórios que favoreçam os interesses por eles representados, os agentes do Estado dependem de informações especializadas de que dispõem os lobistas.

1.14. Apesar de ser fundamental para a consolidação de qualquer regime democrático por seus inequívocos efeitos positivos, o lobby pode também gerar efeitos negativos nas decisões públicas, a depender da forma como praticado. É mister destacar que não são raros os casos em que supostos lobistas, para conseguir convencer os destinatários das suas iniciativas a tomar decisões que satisfaçam os seus interesses, utilizam-se do pagamento ou oferecimento de vantagens indevidas (propina). Esse tipo de iniciativa, entretanto, não se confunde com o lobby, mas com a corrupção e, por isso, deve ser sempre rechaçado.

1.15. Aponta-se que o lobby pode ainda gerar distorções em regimes democráticos, porque se percebe na realidade concreta que nem todos os personagens da vida social dispõem de iguais condições de se fazer representar junto ao Estado. Os estudiosos que se dedicam ao lobby e o observam com perspectiva crítica, embora o compreendam como inerente à vida social, aduzem que ele pode ser fonte geradora de desigualdades, porque muitas vezes favorece apenas os interesses de quem dispõe de elevados recursos econômicos para a contratação de lobistas profissionais.

1.16. Para a neutralização dos riscos próprios da atuação dos lobistas, a qual é salutar para a democracia, é fundamental a criação de diploma normativo que discipline o instituto do lobby, crie balizas a serem observadas na interação entre eles e os agentes públicos, mecanismos que assegurem seja a atividade realizada de forma transparente e sanções para os casos em que verificados comportamentos ilegais. 
1.17. A análise dos sistemas normativos existentes mundo afora indica serem grandes as dificuldades para criar a efetiva disciplina do instituto do lobby, havendo modelos de regulamentação mais complexos e outros mais simples. Assim, há modelos normativos cogentes e outros voluntários; há modelos que apenas exigem dos lobistas prévia identificação; há modelos mais sofisticados, que deles exigem cadastramento prévio, elaboração de relatórios periódicos de informações, divulgação irrestrita dos dados financeiros das suas atividades, identificação de seus clientes e interesses representados, dos funcionários públicos contatados, preveem regras de quarentena para ex-funcionários públicos, controlam financiamentos eleitorais etc., tudo para que se assegure transparência à prática do lobby e à interação dos lobistas com os agentes públicos.

1.18. Há grande diversidade também no que concerne às sanções previstas para os casos de descumprimento normativo, que vão da aplicação de multas e suspensão do exercício de lobby à imposição de sanções penais privativas de liberdade.

2.1. Os Estados Unidos são o país que há mais tempo dispõe de preceitos normativos que têm como fim disciplinar a atuação dos lobistas e assegurar transparência na sua interação com os agentes do Estado, tendo havido ao longo dos anos aprimoramentos importantes sobre a matéria. Atualmente, está vigente o chamado Honest Leadership and Open Government Act, criado no ano de 2007, após a eclosão de graves casos de corrupção envolvendo lobistas e políticos em Washington. Tal diploma normativo define o lobby como qualquer comunicação feita junto a agentes públicos para influenciar a criação ou alteração de leis federais, a criação ou alteração de regulamentação federal, o desenvolvimento de programas ou políticas estatais, a negociação de contratos, a nomeação de agentes públicos etc.

2.2. Para o exercício de suas atividades, o lobista norte-americano deve, obrigatoriamente, de acordo com as previsões normativas, apresentar ao Congresso diversas informações para que seja devidamente credenciado, revelar a identidade e os interesses de seus clientes, encaminhar aos órgãos competentes relatórios trimestrais com informações detalhadas sobre as atividades em favor de cada cliente e os valores relacionados ao lobby. Ademais, cumpre ao lobista, a cada seis meses, elaborar circunstanciados relatórios com apontamentos sobre doações eleitorais ou a qualquer agente ou instituição que possa ter importância em suas atividades.

2.3. O Honest Leadership and Open Government Act veda a concessão de vantagens por lobistas a agentes públicos, contempla regras de quarentena bastante 
rigorosas, estipula a criação de bancos públicos de informações sobre as atividades dos lobistas, e prevê sanções administrativas e criminais nas hipóteses em que pratiquem o lobby em desconformidade com as exigências do texto normativo. Aponta-se, nesse tocante, que a criação de tipo penal para a punição do lobista que age ilegalmente foi a mais importante novidade criada no direito norte-americano sobre a matéria em 2007.

2.4. O Canadá, tal como os Estados Unidos, tem rica experiência no tratamento do instituto do lobby desde o ano de 1989, quando criado o Lobbyist Registration Act. Tal instrumento normativo exigia dos lobistas que se submetessem a cadastramento junto a órgão especializado para que pudessem interagir com agentes do Estado com o propósito de influenciar suas decisões. Posteriormente, no ano de 2008, houve importante reforma, com a criação do Lobbying Act. A partir de então, são obrigados a se cadastrar junto aos órgãos competentes, a revelar os funcionários públicos com os quais interagem, revelar seus clientes e interesses, conhecer com clareza as condutas permitidas e proibidas, além de elaborar relatórios periódicos e detalhados das atividades de lobby realizadas. Ainda, e esse dado é essencial, nas hipóteses de descumprimento dos preceitos normativos, os infratores podem ser punidos civil, administrativa e criminalmente.

2.5. No Reino Unido, por muitos anos, em que pese fosse nítida a sua importância, a atuação dos lobistas não era objeto de incidência normativa direta. A bem da verdade, as normas que, de alguma maneira, impactavam as atividades de lobby criavam balizas para a atuação dos funcionários públicos alvos dos lobistas. Entretanto, conforme se revelava importante que também os lobistas fossem sujeitos a parâmetros mínimos de comportamento, associações privadas que os congregavam passaram a criar textos normativos para os seus membros e associados, cuja observância era voluntária. Essa situação foi substancialmente alterada no ano de 2014, quando criado o Transparency of Lobbying, Non-Party Campaign and Trade Union Administration Act, cuja abrangência é restrita por alcançar apenas o lobby junto a agentes da Coroa britânica, mas evidencia a tendência de regulamentação do instituto. De acordo com o novo diploma normativo, que visa a assegurar a transparência na interação entre agentes públicos e lobistas, estes são obrigados a se cadastrar para desempenhar suas atividades e a enviar aos órgãos competentes, trimestralmente, relatórios circunstanciados de suas atividades. Tal como ocorre nos Estados Unidos e no Canadá, também no Reino Unido é possível a aplicação de sanções criminais aos lobistas que atuem de forma ilegal. 
2.6. Na América Latina, o primeiro país a criar normas para regulamentar o instituto do lobby foi o Chile, a chamada Ley de Lobby, no ano de 2014. Diferentemente do que ocorre em todos os sistemas anteriormente analisados, no sistema normativo chileno as obrigações de registro e de fornecimento de informações para assegurar efetiva transparência às práticas de lobby não recaem sobre o lobista, mas sobre os próprios funcionários públicos que ele busque influenciar. Tal situação tem sido identificada como um dos fatores que motiva os baixos índices de observância normativa, o que também decorre da inexistência de previsões sancionatórias dissuasórias. Assim, o que se tem é que a Ley de Lobby, embora seja a primeira produzida na América Latina para tratar da matéria, não dispõe de sistemática normativa que supra a demanda da sociedade e dos órgãos da administração pública por maior transparência na interação entre lobistas e funcionários da administração pública.

2.7. A União Europeia é responsável pela definição de oitenta por cento de todas as normas que vigem nas nações que a integram. Atualmente, a entidade conta com órgãos que têm como finalidade discutir temas e propostas normativas em diversos setores econômicos, como agricultura, mercado financeiro, infraestrutura, logística, transporte, indústria, comércio etc., o que favoreceu a ocorrência, nas últimas décadas, de verdadeira explosão na quantidade de lobistas ativos em Bruxelas. Estima-se haver nos tempos atuais mais de trinta mil lobistas que atuam junto aos organismos do bloco europeu e diversos grandes conglomerados econômicos que dispõem de equipes especializadas e integralmente dedicadas a praticar o lobby nesse ambiente. Por isso, as discussões sobre a regulamentação do lobby na União Europeia são essenciais, e muitos de seus organismos criaram diplomas normativos próprios para estabelecer critérios para que se admita a atuação dos lobistas. Dada a circunstância de que não eram uniformes as previsões criadas por cada um desses organismos, em 2011, foi celebrado um Acordo Interinstitucional, ainda em fase de implementação, que tem como propósito definir normas padronizadas para reger a atuação dos lobistas em todo o bloco, com a previsão de que se cadastrem para que possam atuar, que disponibilizem à sociedade informações sobre as suas interações com agentes da União Europeia e sejam efetivamente sancionados nas hipóteses de descumprimento normativo.

2.8. Em resumo, é evidente a importância da regulamentação do lobby e a circunstância de que tem sido feita cada vez com mais frequência mundo afora. É imprescindível sejam criados mecanismos efetivos que assegurem a transparência na 
interação necessária e inevitável entre lobistas e agentes públicos e prevejam sanções que inibam a prática de comportamentos ilícitos, em especial, de crimes que afetem o bem jurídico administração pública.

3.1. No Brasil, a prática do lobby está integralmente albergada pela Constituição Federal de 1988 e, tal como acontece em todos os países democráticos do mundo, é usual a equivocada associação da atuação dos lobistas à prática de corrupção, situação que revela a imprescindibilidade de que seja criado diploma normativo que estabeleça distinções claras entre o instituto estudado e o fenômeno corruptivo. No Congresso Nacional, desde o ano de 1989, tramitam projetos legislativos que têm como objetivo disciplinar a atuação dos lobistas, sendo que o que mais recebe atenção dos parlamentares e tem maiores chance de ser aprovado é, inequivocamente, o pior deles. Com efeito, o Projeto de Lei $\mathrm{n}^{\mathrm{o}} 1.202$ do Deputado Carlos Zarattini não cria qualquer obrigação efetiva para os lobistas, pois institui um sistema de cadastramento voluntário e não contempla qualquer sanção efetiva para as hipóteses de atuação ilegal.

3.2. O mais rico projeto de lei vigente é de relatoria do Senador Walter Pinheiro (PL n ${ }^{\circ}$ 336/2015) e prevê diversos mecanismos de controle da atuação dos lobistas que, efetivamente, poderiam assegurar maior transparência às atividades de lobby. Assim, de acordo com as previsões da norma, qualquer pessoa que pretenda adotar medidas para influenciar decisões relativas à criação de regulamentos, realização de procedimentos licitatórios, celebração de contratos, formulação de políticas públicas, outorga de concessões etc., deve, necessária e inicialmente, requerer o seu cadastramento como lobista junto aos órgãos competentes e renová-lo anualmente. Ademais, é prevista a obrigação de fornecimento de informações sobre os interesses que representam, as decisões específicas que buscam influenciar, os valores envolvidos na atividade de lobby etc., e sanções variadas - de natureza exclusivamente administrativa - para as hipóteses de descumprimento das exigências normativas.

3.3. Há vários projetos de lei em tramitação no Brasil para tratar da matéria, porém, nenhum deles o faz de forma satisfatória, dentre outras razões, porque não promovem qualquer tipo de reflexão no que concerne à racionalização do arcabouço jurídico-penal e da previsão de tipo penal específico que alcance as ilegalidades de maior gravidade praticadas em contexto de lobby. Tal reflexão é essencial, pois, como demonstrado alhures, criminalizar comportamentos específicos dos lobistas e de seus contratantes é fundamental 
para o tratamento do instituto, assim como dissociá-los, de forma clara, dos crimes contra a administração pública.

3.4. Em nossa opinião, é imprescindível que, paralelamente à disciplina administrativa das atividades dos lobistas, com a criação de ferramentas jurídicas que assegurem transparência às suas relações com os agentes públicos, sejam realizadas reformulações em diversos preceitos incriminadores da legislação penal brasileira. Tais reformulações são necessárias para que efetivamente sejam respeitados os princípios fundamentais do Direito Penal e para que se promova a racionalização do sistema.

3.5. No tocante aos tipos penais de corrupção ativa e passiva, não deve haver alteração. Com efeito, a prática do lobby é integralmente compatível com os ideais democráticos e em nada se confunde com a celebração de pactos sceleris. Afinal, nas hipóteses de corrupção, os agentes mercadejam vantagens ilegais, em troca de decisões estatais, ao passo que o lobby representa um esforço de convencimento, com alicerce em argumentos racionais - não em propinas —, com o fim de que aqueles que tomam decisões públicas façam escolhas que satisfaçam os interesses daqueles que contratam os lobistas. Portanto, o lobby não envolve a formação de um pacto sceleris entre o lobista e o agente público, não cria estímulos para que o intraneus deixe de cumprir suas obrigações junto à administração pública, situação que evidencia a sua absoluta distinção em relação ao fenômeno da corrupção, sancionado devidamente nos artigos 317 e 333 do Código Penal, que não devem ser alterados.

3.6. É evidente, também, a distinção entre o lobby e a prevaricação, tipificada no artigo 319 do Código Penal e configurada nas hipóteses em que o funcionário público viole as suas obrigações funcionais. Isso porque, o que busca o lobista na interação com funcionários públicos é instrui-los com informações para que as escolhas que façam no exercício de suas funções, dentre aquelas possíveis e legais, sejam as que atendam melhor os seus representados. O lobista não persegue, pois, a obtenção de decisões públicas, senão aquelas que sejam favoráveis a seus clientes e, concomitantemente, compatíveis com o ordenamento jurídico e, em especial, com os postulados fundamentais que sustentam a administração pública. Logo, a prática do lobby, que visa à promoção de interesses públicos e privados junto ao Estado, não apresenta interseções com as modalidades típicas de prevaricação, que se configuram com a prática ou a omissão ilegal de atos de ofícios por agentes públicos para a satisfação de interesses ou sentimentos pessoais, tampouco se confunde com a corrupção privilegiada. Entretanto, para que se alcance efetiva 
proporcionalidade nas previsões sancionatórias do Código Penal, julgamos necessário sejam elevadas as penas previstas nos artigos $317, \S 2^{\circ}$ e 319 do Código Penal a fim de se alcançar efetivo equilíbrio entre a gravidade das condutas neles tipificadas e a gravidade das sanções a serem aplicadas.

3.7. Julgamos ser imprescindível para a racionalização do Direito Penal nacional profunda reformulação dos tipos penais que tratam da chamada advocacia administrativa, com a revogação parcial do artigo 321 do Código Penal e integral do artigo 91 da Lei Federal $n^{\circ} 8.666 / 96$ e do artigo $3^{\circ}$, inciso III da Lei Federal $n^{\circ} 8.137 / 90$. Trata-se, na verdade, de hipóteses nas quais atividades típicas de lobby são desempenhadas por funcionários públicos. Entretanto, se o funcionário público age para promover interesses particulares legítimos junto à administração pública, se o faz sem que seja beneficiado com o recebimento de vantagens indevidas ou sem que pretenda obter com a influência e o prestígio de que goze decisão pública ilegal, não há incidir o Direito Penal, pois não há violação do bem jurídico administração pública. Embora tais atividades devam ser realizadas com transparência e amplamente divulgadas, não podem ser criminalizadas. Essa conclusão, é preciso destacar, não é extensível aos casos, sancionados mais severamente na ordem jurídica brasileira, em que o funcionário público busque defender interesses ilegítimos. Tal comportamento, é evidente, praticado por alguém que deve zelar pelo interesse público e pela realização dos princípios da legalidade, da impessoalidade, da moralidade, da publicidade e da eficiência, afeta o bem jurídico administração pública e, por isso, deve seguir tipificado criminalmente.

3.8. Na mesma esteira, entendemos necessária a revogação integral dos artigos 332 e 357 do Código Penal pátrio, que tipificam, respectivamente, os delitos de tráfico de influência e exploração de prestígio. Essas são, vale dizer, as figuras delitivas existentes em nossa sistemática jurídico-penal que mais pontos de contato têm com o instituto do lobby. Afinal, a configuração dos crimes em questão ocorre nas hipóteses em que o sujeito é remunerado a pretexto de influir em decisões dos agentes do Estado e, com isso, assegurar sejam satisfeitos os interesses de quem o remunera. Ocorre que, no lobby, o lobista busca, de forma efetiva, adotar estratégia de convencimento que vise à promoção dos interesses de seus representados, ao passo que os agentes que praticam as condutas proscritas nos artigos 332 e 357 nada mais fazem do que vender fumaça, afirmando às suas vítimas que devem ser remunerados para exercer influência em face de agentes públicos que, na verdade, não têm. Trata-se, por conseguinte, de verdadeiro engodo que não afeta a 
administração pública e tem estrutura idêntica à do estelionato. Por isso, a nosso juízo, é despicienda a subsistência das figuras típicas do tráfico de influência e da advocacia administrativa em nossa sistemática normativa, porquanto o recebimento de valores, sob a justificativa de que eles são devidos em razão do exercício de influência inexistente junto à administração pública, deve ser sancionado com base no artigo 171 do Código Penal, que proíbe exatamente essa espécie de comportamento.

3.9. Já o tráfico de influência real, no âmbito da administração pública em que a atividade de lobby seja regulamentada, deverá ser sancionado com base no artigo 47 da Lei de Contravenções Penais apenas nas hipóteses em que seja realizado por lobista não cadastrado. De seu turno, o lobista cadastrado que comercialize sua capacidade de influir na atuação dos agentes do Estado, desde que na promoção de interesses legítimos, jamais poderá ser sancionado, pois que sua atividade é essencial à promoção dos valores democráticos e consonante com a sistemática jurídica vigente no país.

4.10. Por fim, entendemos necessária, para a sistematização completa do instituto do lobby na ordem jurídica brasileira, seja sancionado o lobista que, cadastrado, negocie influência efetiva voltada a estimular a prática de ato ilegal por funcionário público. Tal comportamento viola a administração pública, sua moralidade, seu prestígio e seu bom funcionamento, porque o lobista cadastrado assume obrigações especiais para o exercício de suas atividades e, portanto, há de pautar seu comportamento de forma a observar os princípios norteadores da administração pública. Assim, sugerimos sejam criminalizados o tráfico de influências passivo e o tráfico de influências ativo, porque tanto o lobista que se propõe a influenciar a prática de ato ilegal de agente público, quanto quem o contrate para tal fim adotam comportamentos que violam bem jurídico essencial. As condutas que entendemos devam ser tipificadas estão abaixo descritas:

Tráfico de Influência Passivo Para a Prática de Ato de Ofício Ilícito

Solicitar ou receber, quem seja legalmente credenciado para o exercício do lobby, direta ou indiretamente, dinheiro ou qualquer outra utilidade, para influenciar funcionário público ou agente a ele equiparado a retardar, deixar de praticar, ou praticar ato de ofício, de forma ilegal.

Pena - reclusão, de 01 (um) a 05 (cinco) anos e multa, se o fato não constituir crime mais grave.

$\S 1^{\circ}$ - Aplicam-se as mesmas penas às condutas de solicitar ou receber, quem seja legalmente credenciado para o exercício de lobby, direta ou indiretamente, dinheiro ou qualquer outra utilidade, para influenciar juiz, jurado, órgão do Ministério Público, funcionário de justiça, perito, tradutor, intérprete ou testemunha a agir de forma ilegal. 
$\S 2^{\circ}$ - A pena é aumentada em um terço, se o sujeito legalmente credenciado para o exercício do lobby adotar medidas que resultem na atuação ilegal do funcionário público.

Tráfico de Influência Ativo Para a Prática de Ato de Ofício Ilícito

Oferecer, prometer ou conceder, direta ou indiretamente, a quem seja legalmente credenciado para o exercício do lobby, dinheiro ou qualquer outra utilidade, para fazê-lo influenciar funcionário público ou agente a ele equiparado a retardar, deixar de praticar ou praticar ato de ofício, de forma ilegal.

Pena - reclusão, de 06 (seis) meses a 02 (dois) anos e multa, se o fato não constituir crime mais grave.

$\S 1^{\circ}$ - Aplicam-se as mesmas penas às condutas de solicitar ou receber, quem seja legalmente credenciado para o exercício de lobby, direta ou indiretamente, dinheiro ou qualquer outra utilidade, para influenciar juiz, jurado, órgão do Ministério Público, funcionário de justiça, perito, tradutor, intérprete ou testemunha a agir de forma ilegal.

$\S 2^{\circ}$ - A pena é aumentada em um terço, se o sujeito legalmente credenciado para o exercício do lobby adotar medidas que resultem na atuação ilegal do funcionário público.

4.11. Em suma: (i) o lobby jamais poderá ser vedado prima facie, mas deve ser exercido de forma transparente, com o registro prévio de todos os que a ele se dedicam; (ii) o falso lobista (não cadastrado) que negocie influência efetiva ou fictícia sobre ato lícito ou ilícito de funcionário público deve ser sancionado nos termos do artigo 47 da Lei de Contravenções Penais e do artigo 171 do Código Penal; (iii) o lobista cadastrado que negocie influência inexistente para provocar a atuação legal ou ilegal de funcionário público deve ser punido administrativa e criminalmente (artigo 171 do Código Penal); (iv) por fim, o lobista cadastrado que atue com o fim de estimular a prática de ato ilegal de funcionário público deve ser sancionado criminalmente com fundamento em novo tipo penal, nos moldes das condutas típicas acima expostas:

\begin{tabular}{|c|c|}
\hline$\underline{\text { Lobista não-cadastrado }}$ & $\underline{\text { Lobista cadastrado }}$ \\
\hline Venda de fumaça: estelionato & $\begin{array}{l}\text { Venda de fumaça: estelionato + sanção } \\
\text { administrativa }\end{array}$ \\
\hline $\begin{array}{l}\text { Venda de influência real sobre ato lícito do agente } \\
\text { público: artigo } 47 \text { LCP }\end{array}$ & $\begin{array}{l}\text { Venda de influência real sobre ato lícito do agente } \\
\text { público: atípico. }\end{array}$ \\
\hline $\begin{array}{l}\text { Venda de influência real sobre ato ilícito do } \\
\text { agente público: artigo } 47 \text { LCP }\end{array}$ & $\begin{array}{l}\text { Venda de influência real sobre ato ilícito do } \\
\text { agente público: novo tipo penal }\end{array}$ \\
\hline
\end{tabular}




\section{REFERÊNCIAS}

ABANTO VAZQUEZ, Manuel A. Sobre o merecimento de pena do tráfico de influência. In: OLIVEIRA, Willian Terra de et al. (Org.). Direito penal econômico: estudos em homenagem aos 75 anos do Prof. Klaus Tiedemann. São Paulo: LiberArs, 2013. p. $103-$ 122. Disponível em: $<$ http://201.23.85.222/biblioteca/index.asp?codigo_sophia=102801>. Acesso em: 08 ago. 2018.

ABOSO, Gustavo Eduardo. Los delitos de tráfico pasivo y activo de influencias: aspectos esenciales de su configuración. Revista de Derecho Penal, Buenos Aires, n. 1, ago. 2004.

ACKERMAN, Frank; STANTON, Elizabeth; MASSEY, Rachel. European chemical policy and the United States: the impacts of REACH. Global Development and Environment Institute, Working Paper n. 06-06. Medford, Sept. 2006. Disponível em: $<$ http://www.ase.tufts.edu/gdae/Pubs/wp/06-06USREACH.pdf $>$.

AINSWORTH, Scott. Regulating lobbyists and interest group influence. The Journal of Politics, v. 55, n. 1, p. 41-56, Feb. 1993.

; SENED, Itai. The role of lobbyists: entrepreneurs with two audiences. American Journal of Political Science, v. 37, n. 3, p. 834-866, Aug. 1993.

ALLDRIGE, Peter. Reforming the criminal law of corruption. Criminal Law Forum, v. 11, n. 3, 2000 .

ALLIANCE FOR LOBBYING TRANSPARENCY AND ETHICS REGULATION IN THE EU. Bursting the Brussels bubble: the battle to expose corporate lobbying at the heart of the EU. Disponível em: $<$ https://www.altereu.org/sites/default/files/documents/bursting-the-brussels-bubble.pdf $>$. Acesso em: 26 fev. 2017.

ÁLVAREZ VÉLEZ, María Isabel; JÄÄSKELÄINEN, Federico de Montalvo. Los lobbies en el marco de la Unión Europea: una reflexión a propósito de su regulación en España. Federico de Montalvo. UNED. Teoría y Realidad Constitucional, n. 33, p. 353-376, 2014. Disponível em: <http://revistas.uned.es/index.php/TRC/article/download/13025/12018>.

AMERICAN BAR ASSOCIATION. The lobbying manual: a complete guide to federal law governing lawyers and lobbyists. 3. ed. Mar. 2008. Disponível em: $<$ http://apps.americanbar.org/abapubs/lobbyingmanual/docs/Interim-Supplement-toLobby-Manual_rev032308.pdf $>$. Acesso em: 23 abr. 2017.

ANASTASIADIS, Stephanos. Understanding corporate lobbying on its own terms. International Center for Corporate Social Responsability Research, Paper Series, n. 42, University of Nottingham, 2006. Disponível em: $<$ http://citeseerx.ist.psu.edu/viewdoc/download?doi=10.1.1.98.9698\&rep=rep1\&type=pdf $>$. Acesso em: 20 fev. 2017. 
APOLLONIO, Dorie; CAIN, Bruce E.; DRUTMAN, Lee. Access and lobbying: looking beyond the corruption paradigm. Hastings Constitutional Law Quaterly, California, v. 36, n. $1, \quad$ p. $13-50, \quad 2008$ Disponível em: $<$ https://www.researchgate.net/profile/Bruce_Cain/publication/265654601_Access_and_L obbying_Looking_Beyond_the_Corruption_Paradigm\%27/links/54b911070cf28faced626a a8/Access-and-Lobbying-Looking-Beyond-the-Corruption-Paradigm.pdf $>$. Acesso em: 23 jun. 2017.

ARAÚJO, Fabiano de Figueiredo. Os atores de política pública e a regulamentação do lobby no Brasil. Fórum Administrativo, Belo Horizonte, ano 16, n. 179, p. 41-50, jan. 2016.

ARNOLD, R. Douglas. The logic of congressional action. Boston: Yale University Press, 1990.

ASSOCIATION OF CORPORATE COUNSEL. Influencing government: the rules of the game (US Campaign Finance, Lobbying Disclosure, and Gift Laws). Washington: Association of Corporate Counsel, 2015. Disponível em: $<$ http://www.acc.com/_cs_upload/vl/membersonly/InfoPAK/584525_11.pdf $>$. Acesso em: 23 abr. 2017.

ATIEH, Jahad. Foreign agents: updating FARA do protect american democracy. Journal of International Law, v. 31, n. 4, p. 1051-1088, 2010. Disponível em: $<$ https://scholarship.law.upenn.edu/cgi/viewcontent.cgi?article=1133\&context=jil $>$.

AUSTEN-SMITH, David. Information and influence: lobbying for agendas and votes. American Journal of Political Science, Austin, v. 37, n. 3, p. 799-833, Aug. 1993.

; WRIGHT, John. Counteractive lobbying. American Journal of Political Science, Austin, v. 38, n. 1, p. 25-44, Feb. 1994.

BACH, David; UNRUH, Gregory C. Business-government relations in a global economy: broadening the conceptual map. IE Working Paper, 07/12/2004. Disponível em: $<$ http://latienda.ie.edu/working_papers_economia/WP04-37.pdf $>$. Acesso em: 27 fev. 2017.

BAIRD, Marcello Fraganno. O lobby na regulação da propaganda de alimentos da Agência Nacional de Vigilância Sanitária - Anvisa. 2012. Dissertação (Mestrado) Faculdade de Filosofia, Letras e Ciências Humanas, São Paulo, 2012.

BALOSIN, Miruna Andrea. Analyzing EU's lobbying. In: THE PROCEEDINGS OF THE EUROPEAN INTEGRATION - BETWEEN TRADITION AND MODERNITY CONGRESS, 2 $2^{\text {nd }}$, Romania: Editura Universităţii „Petru Maior”, 2009. v. 3, p. 1180-1192. Disponível em: <http://www.diacronia.ro/en/indexing/details/A23686/pdf>. Acesso em 26 fev. 2017.

BALTAZAR JÚNIOR, José Paulo. Crimes federais. 9. ed. São Paulo: Saraiva, 2014. 
BARASKO, Maryann. Dissenting doctors: the internal politics of the AMA during the health care reform debate. In: CIGLER, Allan J.; LOOMIS, Burdett A. Interest groups politics. 8. ed. Washington: CQPress, 2012.

BARONI, Laura; CARROLL, Brendan; CHALMERS, Adam; MUÑOZ MARQUEZ, Luz Maria; RASMUSSEN, Anne. Defining and classifying interest group. Interest Group \& Advocacy, v. 3, n. 2, p. 141-159, June 2014.

BAUMGARTNER, Frank R.; BERRY, Jeffrey M.; HOJNACKI, Marie; KIMBALL, David; LEECH, Beth. Lobbying and policy change: who wins, who loses, and why. Chicago: University of Chicago Press, 2009.

; LEECH, Beth L. Basic interests: the importance of groups in politics and in political science. New Jersey: Princeton University Press, 1998.

The multiple ambiguities of counteractive lobbying. American Journal of Political Science, Wisconsin, v. 40, n. 2, p. 521-542, May 1996.

BERNHAGEN, Patrick. Lobbying and political influence in Britain: evaluating a signalling model of group-government interaction. Universität Manheim Working Papers, n. 141, 2011. Disponível em: <http://www.mzes.uni-mannheim.de/publications/wp/wp141.pdf $>$.

BIBLIOTECA DEL CONGRESO NACIONAL DE CHILE. Historia de la Ley $n^{\circ} 20.730$ : regula el lobby y las gestiones que representen intereses particulares ante las autoridades y funcionarios. Disponível em: $<$ https://www.bcn.cl/historiadelaley/nc/historia-de-laley/4396/>. Acesso em: 14 fev. 2018.

BIRNBAUM, Jeffrey $\mathrm{H}$. The lobbyists: how influence peddlers work their way in Washington. New York: Times Books, 1993.

BITENCOURT, Cezar Roberto. Advocacia administrativa nos crimes licitatórios. Revista Justiça e Sistema Criminal, Curitiba, v. 4, n. 6, p. 85-100, jan./jun. 2012. Disponível em: $<$ http://www.sistemacriminal.org/site/images/revistas/Revista_n.6.pdf $>$. Acesso em: 27 abr. 2018.

. Tratado de direito penal: parte especial 5. 2. ed. São Paulo: Saraiva, 2008.

BLACKWELL, Jeff. The China lobby: influences on U.S.-China Foreing Policy in the Post War Period, 1949-1954. The Forum (Journal of History), v. 2, n. 1, p. 43-58, 2010. Disponível em: <http://www3.nccu.edu.tw/ lorenzo/Blackwell,\%20China\%20Lobby.pdf>.

BLUMBERG, Mark. Lobbying and canadian charities: to register or not to register. Sept. 2008. Disponível em: Disponível em: $<$ http://www.globalphilanthropy.ca/images/uploads/Lobbying_and_Canadian_Charities_T o_register_or_not_to_register.pdf>. Acesso em: 04 abr. 2017.

BOBBIO, Norberto; MATTEUCCI, Nicola; PASQUINO, Gianfranco. Dicionário de política. 4. ed. Brasília-DF: Ed. da UnB, 1992. 
BODDEWYIN, Jean J. The internalizations of the public-affairs function in U.S. multinational enterprises. Business \& Society, v. 46, n. 2, p. 136-173, June 2007.

; BREWER, Thomas L. International-business political behavior: new theoretical directions. Academy of Management Review, v. 19, n. 1, p. 119-143, Jan. 1994.

BOESSEN, Sandra; MAARSE, Hans. A ban on tobacco advertising: the role of interest groups. In: COEN, David; RICHARDSON, Jeremy (Eds.). Lobbying the European Union: institutions, actors, and issues. Oxford: Oxford University Press, 2011. p. 212-232. Disponível em: $<$ http://docenti.unimc.it/andrea.prontera/teaching/2016/15964/files/business-lobbying-inthe-european-union_chapter_8_reading_week_3>.Acesso em: 15 mar. 2017.

BONARDI, Jean-Philippe; HILLMAN, Amy J. The attractiveness of political markets: implications for firm strategy. Academy of Management Review, v. 30, n. 2, p. 397-413, $2005 . \quad$ Disponível em: $<$ https://serval.unil.ch/resource/serval:BIB_676E2CADD102.P001/REF>.

; KEIM, Gerald D. Corporate political strategies for widely salient issues. Academy of Management Review, v. 30, n. 3, p. 555-576, 2005. Disponível em: $<$ https://serval.unil.ch/resource/serval:BIB_511E51D7E940.P001/REF.pdf $>$.

BORGES, Tiago Daher Padovezi. Candidatos, partidos políticos e interesses empresariais: um estudo sobre o financiamento empresarial de campanhas para Deputado Federal. 2013. Tese (Doutorado) - Faculdade de Filosofia, Letras e Ciências Humanas da Universidade de São Paulo. São Paulo, 2013.

BOUWEN, Pieter. A comparative study of business lobbying in the European Parliament, The European Commission and the Council of Ministers. Max-Planck-Institut für Gesellschaftsforschung, MPIfG Discussion Paper, 02/07, Köl, Germany, Nov. 2002. Disponível em: <https://www.mpifg.de/pu/mpifg_dp/dp02-7.pdf $>$. Acesso em: 18 mar. 2018.

. Corporate lobbying in the European Union: the logic of access. Journal of European Public Policy, v. 9, n. 3, p. 365-390, June 2002. Disponível em: $<$ https://pure.mpg.de/rest/items/item_1234563/component/file_2052336/content>.

. The European Commission. In: COEN, David; RICHARDSON, Jeremy (Eds.). Lobbying the European Union: institutions, actors, and issues. Oxford: Oxford University Press, 2011. p. 19-38. Disponível em: $<$ http://docenti.unimc.it/andrea.prontera/teaching/2016/15964/files/business-lobbying-inthe-european-union_chapter_8_reading_week_3>. Acesso em: 15 mar. 2017.

The logic of access to the European Parliament: business lobbying in the Committee on Economic and Monetary Affairs. Journal of Common Market Studies, v. 42, n. 3, p. 473-495, Sept. 2004.

A theoretical and empirical study of corporate lobbying in the European Parliament. European Integration Online Papers (EIoP), v. 7, n. 11, 2003. Disponível em: $<$ www.eiop.or.at/eiop/texte /2003-011a.htm>. Acesso em: 18 mar. 2018. 
BRASIL. Câmara dos Deputados. Decreto $n^{\circ} 847$, de 11 de outubro de 1890. Disponível em: $\quad<$ http://www2.camara.leg.br/legin/fed/decret/1824-1899/decreto-847-11-outubro1890-503086-publicacaooriginal-1-pe.html>. Acesso em: 15 set. 2018.

Câmara dos Deputados. PL 1202/2007. Disciplina a atividade de "lobby" e a atuação dos grupos de pressão ou de interesse e assemelhados no âmbito dos órgãos e entidades da Administração Pública Federal, e dá outras providências. Autor: Carlos Zarattini - PT/SP. Apresentação 30/05/2007. Disponível em: $<$ http://www.camara.gov.br/proposicoesWeb/fichadetramitacao?idProposicao=353631 $>$. Acesso em: 08 jul. 2017.

Câmara dos Deputados. PL 1961/2015. Disponível em: $\overline{<\mathrm{https}}$ //www.camara.gov.br/proposicoesWeb/fichadetramitacao?idProposicao=1344449>. Acesso em: 10 out. 2017.

Câmara dos Deputados. PL 6132/1990. Disponível em:

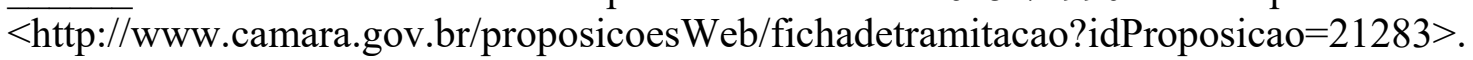
Acesso em: 08 out. 2017.

$\begin{array}{cccc} & \text { Câmara dos Deputados. Projeto de Lei } & \text { n. } & 6.132-A \text {, de } 1990 \text { (Do Senado Federal) } \\ N^{o} & \text { 203/89. } & \text { Disponível }\end{array}$ $<$ www.camara.gov.br/proposicoesWeb/prop_mostrarintegra;jsessionid=A1A6AB70CC7C 4A6642584A961EB941A1.proposicoesWebExterno2? codteor=982371\&filename=Dossie +-PL+6132/1990>. Acesso em: 08 out. 2017.

Câmara dos Deputados. Projeto de Lei $n^{o}$ 6665, de 2016. (Da Comissão de Legislação Participativa). Disponível em: $<$ http://www.camara.gov.br/proposicoesWeb/prop_mostrarintegra;jsessionid=639B7AE09 20C109D706167C70FBE711A.proposicoesWebExterno2? codteor $=1516349 \&$ filename $=\mathrm{P}$ L+6665/2016>. Acesso em: 15 set. 2018.

. Senado Federal. Projeto de Lei do Senado $n^{\circ} 336$, de 2015. Disponível em:

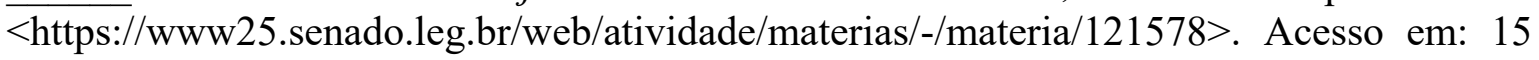
set. 2018.

. Senado Federal. Proposta de Emenda à Constituição $n^{\circ} 47$, de 2016. Disponível em: $<$ https://www25.senado.leg.br/web/atividade/materias/-/materia/126981>. Acesso em: 15 set. 2018.

BROGAN, Pamela. The torturers' lobby: how human rights-abusing nations are represented in Washington. Washington: The Center for Public Integrity, 1992.

BRONZATTO, Thiago. Ouça o áudio em que lobista negocia propina para líder do PTB. Veja, São Paulo, 31 maio 2018. Disponível em: <https://veja.abril.com.br/politica/ouca-oaudio-em-que-lobista-negocia-propina-para-lider-do-ptb/>. Acesso em: 18 set. 2018.

BROSCHEID, Andreas; COEN, David. Insider and outsider lobbying of the European Commission. European Union Politics, v. 4, p. 165-189, June 2003. 
CAMPOS, Nauro F.; GIOVANNONI, Francesco. Lobbying, corruption and political influence. IZA Discussion Paper n. 2313, Bonn, Sept. 2006. Disponível em: $<$ https://pdfs.semanticscholar.org/5a4a/385a8447f47370306d8a72742b0a1fcf0ac2.pdf $>$.

CANADA. Federal Court of Appeal. Democracy Watch v. Campbell, [2010] 2 FCR 139, $2009 \quad F C A \quad 79$ (CanLII). Disponível em: $<$ https://www.canlii.org/en/ca/fca/doc/2009/2009fca79/2009fca79.html?searchUrlHash=A AAAAQAZImRhdmlkIGJha2VyliBvciBiYWtlcmxhdwAAAAAB $>$. Acesso em: 16 jul. 2017.

. Office of the Commissioner of Lobbying of Canada. Active Lobbyists and Registrations by Type. Disponível em: $<$ https://lobbycanada.gc.ca/app/secure/ocl/lrs/do/lbsRegs>. Acesso em: 02 jul. 2017.

. Office of the Commissioner of Lobbying of Canada. Annoted Lobbysts' Code of Conduct (2015). Ottawa, Ontario: Office of the Commissioner of Lobbying of Canada, 2015. Disponível em: <https://lobbycanada.gc.ca/eic/site/012.nsf/eng/h_01185.html >. Acesso em: 26 fev. 2017.

Office of the Commissioner of Lobbying of Canada. Annual Report 2016-17. Ottawa: Office of the Commissioner of Lobbying of Canada, 2017. Disponível em: $<$ https://lobbycanada.gc.ca/eic/site/012.nsf/vwapj/OCL_AR16-

17.pdf/\%24FILE/OCL_AR16-17.pdf>. Acesso em: 02 jul. 2017; 16 jan. 2018.

. Office of the Commissioner of Lobbying of Canada. Lobbying Act. Disponível $\overline{\mathrm{em}:}<\mathrm{h} t \mathrm{tps}: / /$ lobbycanada.gc.ca/eic/site/012.nsf/eng/h_00009.html $>$. Acesso em: 02 jul. 2017.

Disponível

Office of the Commissioner of Lobbying of Canada. Lobbyists' Code of Conduct.

$<$ https://lobbycanada.gc.ca/eic/site/012.nsf/vwapj/LobbyistsCodeofConduct2015_En.pdf/

\%24FILE/LobbyistsCodeofConduct2015_En.pdf $>$. Acesso em: 28 jan. 2018.

Office of the Commissioner of Lobbying of Canada. Registry Search and Statistics. Disponível em: <https://lobbycanada.gc.ca/eic/site/012.nsf/eng/00035.html>. Acesso em: 02 jul. 2017.

. Office of the Commissioner of Lobbying of Canada. Reports on Investigation. Disponível em: <https://lobbycanada.gc.ca/eic/site/012.nsf/eng/h_00016.html >. Acesso em: 02 jul. 2017.

. Office of the Commissioner of Lobbying of Canada. Reports and Publications. Disponível em: <https://lobbycanada.gc.ca/eic/site/012.nsf/eng/h_00017.html>. Acesso em: 02 jul. 2017.

Office of the Commissioner of Lobbying of Canada. Subject Matter in Active Registrations. Disponível em: <https://lobbycanada.gc.ca/app/secure/ocl//rs/do/regSms>. Acesso em: 02 jul. 2017. 
CARBAJO CASCÓN, Fernando. Corrupción pública, corrupción privada y derecho privado patrimonial: una relacíon instrumental. Uso perverso, prevención y represión. In: RODRÍGUEZ GARCÍA, Nicolás; FABIÁN CAPARRÓS, Eduardo A. (Coords.). La corrupción en un mundo globalizado: análisis interdisciplinar. Salamanca: Ratio Legis, 2004.

CARLONI, Enrico. Regolazione del "lobbying" e politiche anticorruzione. Rivista Trimestrale di Diritto Pubblico, Milano, n. 2, p. 371-411, apr./giug. 2017.

CARNEIRO, Mariana. Cartórios fazem lobby contra cadastro positivo. Folha de S. Paulo, São Paulo, 25 abr. 2018. Disponível em: $<$ https://www1.folha.uol.com.br/mercado/2018/04/cartorios-fazem-lobby-contra-cadastropositivo.shtml>. Acesso em: 02 set. 2018.

CARRAZAI, Estelita Hass; BÄCHTOLD, Felipe; ALBUQUERQUE, Ana Luiza. Lobista do PMDB admite pagamentos de propina e implica Renan e Jader. Folha de S. Paulo, São Paulo, 19 jul. 2017.2 Disponível em: $<$ https://www1.folha.uol.com.br/poder/2017/07/1902697-lobista-do-pmdb-admitepagamentos-de-propina-e-implica-renan-e-jader.shtml>. Acesso em: 15 set. 2018.

CARTOLANO SCHIAFFINO, Mariano Jorge. El tráfico de influencias en el Código Penal español: una respuesta penal frente a la corrupción. Revista de Derecho Penal, Procesal Penal y Criminología, v. 3, 2003.

CAULKIN, Simon; COLLINS, Joanna. The private life of public affairs. London: Green Alliance, 2003.

THE CENTER FOR PUBLIC INTEGRITY. Disponível em: $<$ http://projects.publicintegrity.org/lobby/profile.aspx $?=$ countries\&year $=2003=c 0=$ ca\&sub $=1>$. Acesso em: 01 jul. 2017.

CHAGAS, Lucas Squarize. Estratégia e lobby: uma análise da interação entre grupos econômicos e contribuição de campanha. 2014. Dissertação (Mestrado) - Faculdade de Economia, Administração e Contabilidade da Universidade de São Paulo. São Paulo, 2014.

CHAMBERS, Anthony. The lobbying of the EU: how to achieve greater transparency. Civitas: Institute for the Study of Civil Society, London, Feb. 2016. Disponível em: $<$ http://www.civitas.org.uk/content/files/Anthony-Chambers-EU-lobbying.pdf $>$. Acesso em: 15 mar. 2017.

CHARI, Raj; HOGAN, John; MURPHY, Gary. Regulating lobbying: a global comparison. New York: Manchester University Press, 2010. (European Policy Research Unit Series).

; _ _ _ Regulating lobbying: a global comparison. New York: Manchester University Press, 2012. (European Policy Research Unit Series).

; MURPHY, Gary. Examining and assessing the regulation of lobbyists in Canada, the USA, the EU Institutions, and Germany: a report for the department of the environment, heritage and local government. Dublin: 2006. Disponível em: $<$ https://www.transparency.ie/sites/default/files/2006_Registration_of_Lobbyists.pdf $>$. Acesso em: 04 abr. 2017. 
CHARI, Raj; O'DONAVON, Daniel Hillebrand. Lobbying the European Commission: open or secret? Working Papers Series in Economic and Social Science, Madrid, p. 104124, July 2011.

CHARRAD, Kristina. Lobbying the European Union. NEZ - Nachwuchsgruppe Europäische Zivilgesellschaft, Westfälische Wilhelms-Universität Münster, 2005. 24 p. Disponível em: $<$ http://lobbyists.ru/eu/Charrad_Literaturbericht_Lobbying_mit_Deckblatt.pdf $>$. Acesso em: 25 fev. 2018.

CHILE. Congreso Nacional. Ministerio Secretaría General de la Presidencia. Ley 20730. Regula el Lobby y las Gestiones que Representen Intereses Particulares ante las Autoridades y $\quad$ Funcionarios. Disponível em: $<$ https://www.leychile.cl/Navegar?idNorma=1060115>. Acesso em: 13 fev. 2018.

CIGLER, Allan J. Interest group money in the 2008 federal election. In: CIGLER, Allan J.; LOOMIS, Burdett A. (Eds.). Interest groups politics. 8. ed. Washington: CQPress, 2012.

CIGLER, Beverly A. Not just another special interest: the intergovernmental lobby rivisited. In: CIGLER, Allan J.; LOOMIS, Burdett A. (Eds.). Interest groups politics. 8. ed. Washington: CQPress, 2012.

CODIGO Philippino, ou, Ordenações e leis do Reino de Portugal: recopiladas por mandado d'El-Rey D. Philippe I. Disponível em: $<$ http://www2.senado.leg.br/bdsf/item/id/242733>. Acesso em: 15 set. 2018.

COEN, David. Business lobbying in the European Union. In: COEN, David; RICHARDSON, Jeremy (Eds.). Lobbying the European Union: institutions, actors, and issues. Oxford: Oxford University Press, 2011. p. 145-168. Disponível em: $<$ http://docenti.unimc.it/andrea.prontera/teaching/2016/15964/files/business-lobbying-inthe-european-union_chapter_8_reading_week_3>. Acesso em: 15 mar. 2017.

. Empirical and theoretical studies in EU lobbying. Journal of European Public Policy, v. 14, n. 3, p. 333-345, Apr. 2007.

Environmental and business lobbying alliances in Europe: learning from Washington? In. LEVY, D.; NEWELL, P. (Eds.). The business of global environmental governance. Cambridge: MIT Press, 2004.

. The European business lobby. Business Strategy Review, London, Business School, v. 8, p. 17-25, Dec. 1997.

. The impact of U.S. lobbying practice on the european business-government relationship. California Management Review, University of California, Berkeley, v. 41, n. 4, p. 27-44, July 1999.

. Lobbying in the European Union. Constitutional Affairs, PE 393.266, Nov. 2007.

Brussels: $\quad$ European $2007 . \quad$ Darliament, em: $<$ http://www.eurosfaire.prd.fr/7pc/doc/1211469722_lobbying_eu.pdf $>$. Acesso em: 25 fev.; 27 maio 2018. 
COEN, David; RICHARDSON, Jeremy. Institutionalizing and managing intermediation in the EU. In: COEN, David; RICHARDSON, Jeremy (Eds.). Lobbying the European Union: institutions, actors, and issues. Oxford: Oxford University Press, 2011. p. 337-349. Disponível

em: $<$ http://docenti.unimc.it/andrea.prontera/teaching/2016/15964/files/business-lobbying-inthe-european-union_chapter_8_reading_week_3>. Acesso em: 15 mar. 2017.

Learning to lobby the European Union: 20 years of change. In: COEN, David; RICHARDSON, Jeremy (Eds.). Lobbying the European Union: institutions, actors, and issues. Oxford: Oxford University Press, 2011. p. 3-15. Disponível em: $<$ http://docenti.unimc.it/andrea.prontera/teaching/2016/15964/files/business-lobbying-inthe-european-union_chapter_8_reading_week_3>. Acesso em: 15 set. 2018. Acesso em: 15 mar. 2017.

COLLISHAW, Neil. History of tobacco control in Canada. Ontario, Nov. 2009. Disponível em: $\quad<$ http://www.smokefree.ca/pdf_1/2009/history $\% 20$ of $\% 20$ tobacco $\% 20$ control $\% 20 \mathrm{in} \% 20$ canada.pdf $>$. Acesso em: 28 fev. 2017.

COMAN, Ramona. Towards regulating lobbying in Romania: a multi-faceted coin. Perspective on European Politics and Society, v. 7, n. 2, p. 155-169, June 2006.

COMISSÃO DAS COMUNIDADES EUROPEIAS. Bruxelas, 3.5.2006. COM(2006) 194 final. Livro Verde. Iniciativa Europeia em Matéria de Transparência. Disponível em: $<$ http://eur-lex.europa.eu/legal-

content/PT/TXT/PDF/?uri=CELEX:52006DC0194\&from=PT>. Acesso em: 10 mar. 2018.

COMISSÃO EUROPEIA. Agreement between the European Parliament and the European Commission on the establishment of a transparency register for organisations and selfemployed individuals engaged in EU policy-making and policy implementation. Disponível em:

$<$ http://eur-lex.europa.eu/legalcontent/pt/TXT/?uri=uriserv:OJ.L_.2011.191.01.0029.01.ENG $>$. Acesso em: 17 mar. 2018 .

. Comunicação 93/C 63/02. Um diálogo aberto e estruturado entre a Comissão os grupos de interesses especiais. Jornal Oficial das Comunidades Europeias, 5 de março de 1993. Disponível em: <http://eur-lex.europa.eu/legalcontent/PT/TXT/?uri=OJ:C:1993:063:TOC>. Acesso em: 10 mar. 2018.

. Direções-gerais, serviços e agências executivas. Disponível em: $\overline{<\mathrm{https}}$ //ec.europa.eu/info/departments_pt>. Acesso em: 15 set. 2018.

Proposta de Acordo Interinstitucional sobre um registo de transparência obrigatório. Bruxelas, 28.9.2016. COM/2016/0627 final. Disponível em: <http://eurlex.europa.eu/legal-content/pt/TXT/?uri=CELEX:52016PC0627>. Acesso em: 18 mar. 2018 .

CONHEÇA as 10 medidas contra a corrupção (Propostas do Ministério Público Federal apoiadas pelos Ministérios Públicos de todo o Brasil). Disponível em: $<$ http://www.mppr.mp.br/pagina-6193.html>. Acesso em: 15 set. 2018. 
CONSENTINO, Luciano. Interesses organizados na cena internacional: o lobby do etanol. 2011. Dissertação (Mestrado) - Faculdade de Filosofia, Letras e Ciências Humanas da Universidade de São Paulo, São Paulo: 2011.

COOK, Constance Ewing. Lobbying for higher education: how colleges and universities influence federal policy. Michigan: Vanderbilt University Press, 1998.

CORPORATE EUROPE OBSERVATORY. Brussels: the EU Quarter, sept. 2011. Disponível em: $<$ https://corporateeurope.org/sites/default/files/publications/ceolobbylow.pdf $>$. Acesso em: 04 abr. 2017.

COSTA, Álvaro Mayrink. Criminalidade na administração pública: peculato, corrupção, tráfico de influência e exploração de prestígio. Revista da EMERJ, Rio de Janeiro, v. 13, n. $52,2010$.

COSTA, Helena Regina Lobo da. Corrupção na história do Brasil: reflexões sobre suas origens no período colonial. In: DEL DEBBIO, Alessandra; MAEDA, Bruno Carneiro; AYRES, Carlos Henrique (Coords.). Temas de anticorrupção e compliance. Rio de Janeiro: Elsevier, 2013.

COSTA, Lucas Nascimento Ferraz. Modelos de lobby no processo constituinte de 198788. Revista de Discentes de Ciência Politica da UFSCAR, v. 3, n. 1, p. 70-97, 2015.

COSTA JÚNIOR, Heitor; BATISTA, Nilo. Casos de direito penal: parte especial. 4. ed. Rio de Janeiro: Lumen Juris, 2001.

COSTA JÚNIOR, Paulo José da. Comentários ao Código Penal. 6. ed. São Paulo: Saraiva, 2000.

; PAGLIARO, Antônio. Crimes Contra a Administração Pública. 2. ed. São Paulo: Malheiros Ed., 1999.

CÔTÉ, André C. Quebec's Experience: developing a legal framework for lobbying and lobbyist registration. In: OCDE. Lobbyists, government and public trust: increasing transparency through legislation. OCDE, 2009. v. 1. This chapter was prepared by André C. Côté. Disponível em: <http://www.oecd.org/publications/lobbyists-governments-andpublic-trust-volume-1-9789264073371-en.htm>. Acesso em: 03 jul. 2018.

CREPAZ, Michele; CHARI, Raj. The EU's initiatives to regulate lobbyists: good or bad administration? Cuadernos Europeos de Deusto, Bilbao, Instituto de Estudios Europeus, n. 51, p. 71-97, Oct. 2014. Disponível em: $<$ http://ced.revistas.deusto.es/article/viewFile/807/939>.

CUGAT, Mauri. Trafico de influencias. In: ARROYO ZAPATERO, Luis; NIETO MARTÍN, Adán. (Coords.). Fraude y corrupción en el derecho penal económico europeo: eurodelitos de corrupción y fraude. Cuenca: Ediciones de la Universidad Castilla-La Mancha, 2006. 
DEAKIN, James. The lobbyist. Washigton: Public Affairs Press, 1966.

DEMOCRACY Watch v. Campbell 2009. Disponível em: $<$ https://www.canlii.org/en/ca/fca/doc/2009/2009fca79/2009fca79.html?searchUrlHash=A AAAAQAZImRhdmlkIGJha2VyIiBvciBiYWtlcmxhdwAAAAAB $>$. Acesso em: 16 jul. 2017.

DENZAU, Arthur T.; MUNGER, Michael C. Legislators and interest groups: how unorganized interests get represented. The American Political Science Review, v. 80, n. 1, p. 89-106, Mar. 1986.

DICIONÁRIO online de português. Disponível em: <https://www.dicio.com.br/pretexto> Acesso em: 15 dez. 2018.

DIRCEU voou 100 vezes em jatinhos como pagamento de propina, diz lobista. Jornal da Band, 26 jan. 2016. Disponível em: <https://videos.band.uol.com.br/15748954/dirceuvoou-100-vezes-em-jatinhos-como-pagamento-de-propina-diz-lobista.html $>$. Acesso em: 08 nov. 2017.

DOVER, Agnes P.; GILLILAND, Michael; BELL, Michael J. Lobbying Disclosure Act. Briefing Papers, Second Series, v. 8, n. 8, p. 1-16, July 2008. Disponível em: $<$ https://www.hoganlovells.com/ /media/hogan-lovells/pdf/publication/briefing_pdf.pdf $>$. Acesso em: 12 out. 2017.

DRAGOJLOVIC, Predrag. Lobbying as a method of business communication. Skola Biznisa, Broj 3, p. 106-113, 2010. Disponível em: <www.vps.ns.ac.rs/SB/2010/3.13.pdf>. Acesso em: 04 abr. 2017.

DREW, Elizabeth. Politics and money: the new road to corruption. New York: MacMillan, 1984.

DREYER, Emmanuel. Droit pénal spécial. 2. ed. Paris: Ellipses, 2012.

DRUMMOND, J. de Magalhães. Comentários ao Código Penal. Rio de Janeiro: Forense, 1944. v. 9.

DRUTMAN, Lee. Trade associations, the collective action dilemma, and the problem of cohesion. In: CIGLER, Allan J.; LOOMIS, Burdett A. Interest groups politics. 8. ed. Washington: CQPress, 2012.

DÜR, Andreas; DE BIÈVRE, Dirk. The question of interest groups influence. International Public Policy, Cambridge, v. 27, n. 1, p. 1-12, May 2007. Disponível em: $<$ https://www.researchgate.net/profile/Andreas_Duer/publication/228394385_The_Questio n_of_Interest_Group_Influence/links/0a85e5379c096e24ce000000/The-Question-ofInterest-Group-Influence.pdf>. Acesso em: 20 set. 2017.

DYCK, Rand. Canadian politics: critical approaches. 4. ed. Toronto: Thomson Nelson, 2004. 
EISING, Rainer. Interest groups in EU policy-making. Living Reviews in European Governance, v. 3, n. 4, p. 4-32, Sept. 2008. Disponível em: $<\mathrm{http}$ //www.europeangovernance-livingreviews.org/Articles/lreg-2008-4/download/lreg2008-4Color.pdf $>$. Acesso em: 19 ago. 2017.

ENOMOTO, Livia Yuri de Queiroz. Influência e disputa regulatória: a atuação de grupos de interesses do setor privado na definição da neutralidade da rede no Brasil. 2017. Dissertação (Mestrado) - Faculdade de Filosofia, Letras e Ciências Humanas, da Universidade de São Paulo, São Paulo, 2017.

EUROPEAN UNION. Delegation of the European Commission to the USA. Lobbying in the EU: an overview. Disponível em: <http://www.lobbyists.ru/eu/9.pdf>. Acesso em: 19 maio 2018.

FAGAN-WATSON, Ben; ELLIOT, Bridget; WATSON, Tom. Lobbying by trade associations on EU climate policy. Policy Studies Institute, London, Mar. 2015. Disponível em:

$<$ http://www.psi.org.uk/pdf/2015/PSI\%20Report_Lobbying\%20by\%20Trade\%20Associati ons\%20on\%20EU\%20Climate\%20Policy.pdf>.

FAORO, Raymundo. Os donos do poder: formação do patronato político brasileiro. 3. ed. São Paulo: Globo, 2007.

FERNÁNDEZ RODRÍGUEZ, María Dolores. Determinados abusos en el ejercicio de la función pública (proyecto de 1980). Anuario de Derecho Penal y Ciencias Penales, v. 34, n. 2/3, p. 485-492, 1981. Disponível em: $<$ https://www.boe.es/publicaciones/anuarios_derecho/abrir_pdf.php?id=ANU-P-198120048500492_ANUARIO_DE_DERECHO_PENAL_Y_CIENCIAS_PENALES_Determi nados_abusos_en_el_ejercicio_de_la_funci\%F3n_p\%FAblica_(Proyecto_de_1980)>.

FIGUEIREDO, John M. de; CAMERON, Charles M. Endogenous cost lobbying: theory and evidence. July 2006.2 Disponível $<$ https://www.princeton.edu/ ccameron/CostLobbying.pdf $>$. Acesso em: 22 abr. 2017.

; TILLER, Emerson H. The structure and conduct of corporate lobbying: how firms lobby the federal communications. Journal of Economics \& Management Strategy, v. 10, n. 1, p. 91-122, Mar. 2001.

FIGUEIREDO, Ney Lima. O lobby no Brasil: uma trajetória histórica. Revista Brasileira de Comunicação Organizacional e Relações Públicas, São Paulo, v. 8, n. 14, p. 181-189, $2011 . \quad$ Disponível em: $<$ http://www.revistas.usp.br/organicom/article/view/139093/134442>. Acesso em: 02 jun. 2017.

FINER, S. E. Anonymous empire: a study of the lobby in Great Britain. London: The Pall Mall Press Limited, 1958.

FLICKER, Scott M. Agents of influence. Pacific Basin Law Journal, v. 9, n. 1-2, p. 275$280,1991$. 
FONSECA FILHO, Luciano Roberto Corrêa da. História, política e cerveja: a trajetória do lobby da indústria da cerveja. 2008. Dissertação (Mestrado) - Faculdade de Filosofia, Letras e Ciências Humanas da Universidade de São Paulo, São Paulo, 2008.

FOULOY, Christian D. European Parliament's report on lobbying. European Parliament's Report on Lobbying. Disponível em: $<$ http://www.aalep.eu/sites/default/files/documents/European\%20Parliament's\%20Report \%20on\%20Lobbying.pdf>. Acesso em: 28 fev. 2017.

FRAGOSO, Heleno Cláudio. Código Penal comentado. 11. ed. Rio de Janeiro: Freitas Bastos, 2000.

. Lições de direito penal. 2. ed. São Paulo: Jose Bushatsky Editor, 1965. v. 4.

FRASSÃO, Caroline de Souza. Lobby e proteção da indústria: uma análise do plano Brasil Maior. 2017. Dissertação (Mestrado) - Faculdade de Filosofia, Letras e Ciências Humanas da Universidade de São Paulo, São Paulo, 2017.

FREEMAN, R. Edward. The politics of stakeholders theory: some future directions. Business Ethics Quarterly, v. 4, n. 4, p. 409-421, Oct. 1994.

; REED, David. Stockholders and stakeholders: a new perspective on corporate governance. California Management Review, v. 25, n. 3, p. 88-106, 1983. Disponível em: $<$ https://www.researchgate.net/profile/R_Freeman/publication/238325277_Stockholders_a nd_Stakeholders_A_New_Perspective_on_Corporate_Governance/links/5893a4b2a6fdcc4 $5530 \mathrm{c} 2 \mathrm{ee} 7 /$ Stockholders-and-Stakeholders-A-New-Perspective-on-CorporateGovernance.pdf $>$.

GARCÍAS PLANAS, Gabriel. El nuevo delito de tráfico de influencias. Revista del Poder Judicial, n. 29, p. 21-33, 1993.

GARÍN GONZALÉZ, Renato. The Chilean Lobbying Act: legal analysis and criticism. 2015. Degree of Magister Juris, University of Oxford, 2015. Disponível em: $<$ https://www.ucursos.cl/inap/2016/1/ELE661/1/material_docente/bajar?id_material=1291791>. Acesso em: 18 dez. 2017.

GAWANDE, Kishore; KRISHNA, Pravin; ROBBINS, Michael J. Foreing lobbies and US trade policy. National Bureau of Economic Research Working Paper Series (Working Paper 10205), Cambridge, MA, Jan. 2004. Disponível em: $<$ https://www.nber.org/papers/w10205.pdf $>$.

GEHRKE, Linda L. Annual Report of the Lobbyst Registrar for the Year 2015. Toronto Office of the Lobbyist Registrar. Mar. 22, 2016. Disponível em: $<$ http://www.toronto.ca/legdocs/mmis/2016/cc/bgrd/backgroundfile-91504.pdf $>$. Disponível em: 26.02.2017.

GELAK, Deanna R. Lobbying and advocacy: winning strategies, recommendations, resources, ethics and ongoing compliance for lobbyists and Washington advocates. Alexandria, VA.: The Capitol.Net, 2008. 
GILENS, Martin; PAGE, Benjamin. Testing theories of american politics: elites, interest groups, and average citizens. Perspective on Politics, v. 12, n. 3, p. 564-591, 2014. Disponível em: $\quad<$ https:/www.cambridge.org/core/services/aop-cambridgecore/content/view/62327F513959D0A304D4893B382B992B/S1537592714001595a.pdf/te sting_theories_of_american_politics_elites_interest_groups_and_average_citizens.pdf $>$.

GILI PASCUAL, Antoni. Bases para la delimitación del ámbito típico en el delito de corrupción privada: contribución al análisis del art. 286 bis del Código Penal según el Proyecto de Reforma de 2007. Revista Brasileira de Ciências Criminais, São Paulo, v. 20, n. 97, p. 217-282, jul./set. 2012.

GIORNO, Guy. Staying on the right side of the law. In: THIRD Annual Government Relations Summit. Ontario: Ottawa, Feb. 2006.

GOBIERNO DE CHILE. Ley $n^{o} 20.730$ que regula el lobby. Disponível em: $<$ https://www.leylobby.gob.cl/files/manual_ciudadano\%20ley_lobby.pdf>.

. Manual jurídico de la Ley $n^{\circ} 20.730$. Que regula el lobby y las gestiones que representen intereses particulares ante las autoridades y funcionários. Disponível em: $<$ https://www.leylobby.gob.cl/files/manual_juridico\%20ley_lobby.pdf $>$. Acesso em: 14 fev. 2018.

$\overline{\text { Lobbistas }}$

. Ministerio Secretaría General de la Presidencia. Código de Buenas Prácticas para

$<$ https://Www.eylobby.gob.cl/files/buenas Disponivel 2018.

GODWIN, Ken; AINSWORTH, Scott H.; GODWIN, Erik. Lobbying and policymaking: the public pursuit of private interests. Los Angeles: Congress Quarterly Press, 2013.

GOLDSTEIN, Kenneth M. Interest groups, lobbying, and participation in America. Cambridge: Cambridge University Press, 1999.

GOLLOB, Justin; LECKRONE, J. Wesley. The effectiveness of intergovernmental lobbying mechanisms in the American Federal System. Fédéralisme Régionalisme, Liége, v. $12,2012$.

GÓMEZ DE LA TORRE, Ignacio Berdugo; CERINA, Giorgio Dario. Sobre la corrupción entre particulares: convenios internacionales y derecho comparado. Revista Brasileira de Ciências Criminais, São Paulo, v. 19, n. 89. p. 159-213, mar./abr. 2011.

GONTIJO, Conrado Almeida Corrêa. O crime de corrupção no setor privado. 1. ed. São Paulo: LiberArs, 2016.

GORDON, Neil. State lobbyists near the $\$ 1$ billion mark. Disponível em: $<$ https://www.publicintegrity.org/2005/08/10/5905/state-lobbyists-near-1-billion-mark>. Acesso em: 23 abr. 2017. 
GRANT, Wyn. Pressure groups and british politics. London: Macmillan, 2000.

GREER, Scott L. The changing world of european health lobbies. In: COEN, David; RICHARDSON, Jeremy (Eds.). Lobbying the European Union: institutions, actors, and issues. Oxford: Oxford University Press, 2011. p. 189-211. Disponível em: $<$ http://docenti.unimc.it/andrea.prontera/teaching/2016/15964/files/business-lobbying-inthe-european-union_chapter_8_reading_week_3 >. Acesso em: 15 mar. 2017.

GRIFFIN, Jennifer J.; DUNN, Paul. Corporate public affairs: commitment, resources, and structure. Business \& Society, v. 43, n. 2, p. 196-220, June 2004.

GUÉGUEN, Daniel. European lobbying. 2. ed. Bruxelas: Europolitics, 2007.

GUYER, Robert L. Guide to State Legislative lobbying. 3. ed. Gainesville: The Law, 2007.

HABIB, Sérgio. Brasil: quinhentos anos de corrupção. Porto Alegre: Antônio Fabris, 1994.

HAGLUND, David; MCNEIL-HAY, Tyson. The Germany lobby and US foreign policy: what, if anything, does it tell us about the debate over the Israel lobby? Ethnopolitics, v. 10, n. 3/4, p. 321-344, Sept./Nov. 2011.

HAIJA, Rammy M. The armageddon lobby: dispensationalist christian zionism and the shaping of US policy towards Israel-Palestine. Holy Land Studies: a multidisciplinary journal, v. 5, n. 1, p. 75-95, May 2006.

HALL, Richard; ANDERSON, Richard. Issue advertising and legislative advocacy in health politics. In: CIGLER, Allan J.; LOOMIS, Burdett A. (Eds.). Interest groups politics. 8. ed. Washington: CQPress, 2012.

; DEARDORFF, Alan V. Lobbying as legislative subsidy. American Political Science Review, v. 100, n. 1, Feb. 2006.

HALPIN, Darren R.; NOWNES, Anthony J. Reappraising the survival question: why we should focus on interest group organizational form and careers. In: CIGLER, Allan J.; LOOMIS, Burdett A. (Eds.). Interest Groups Politics. 8. ed. Washington: CQPress, 2012.

; WARHURST, John. Commercial lobbying in Australia: exploring the Australian Lobby Register. Australian Journal of Public Administration, v. 75, n. 1, p. 1-12, July 2015.

HARRIS, Phil. The evolution of strategic political lobbying in the UK and the psychological network underpinning machiavellian marketing. Journal of Political Marketing, London, v. 1, n. 1, p. 238-251, 2002.

; MCGRATH, Conor. Political marketing and lobbying: a neglected perspective and research agenda. Journal of Political Marketing, v. 11, n. 1/2, p. 75-94, 2012. 
HARSTAD, Bard; SVENSSON, Jakob. Bribe or lobby? It's a matter of development. Northwestern University, 2005. Disponível em: $<$ http://citeseerx.ist.psuedu/viewdoc/download?doi=10.1.1.169.3852\&rep=rep1\&type=pdf $>$. Acesso em: 10 abr. 2017.

105, n. 1, p. 43-63, Feb. 2011.

. Bribes, lobbying and development. American Political Science Review, v.

HAUSER, Henry. European Union lobbying Post-Lisbon: an economic analysis. Berkeley Journal of International Law, v. 29, n. 2, p. 680-709, 2011. Disponível em: $<$ https://scholarship.law.berkeley.edu/cgi/viewcontent.cgi?article=1411\&context=bjil $>$. Acesso em: 15 mar. 2017.

HAYES-RENSHAW, Fiona. Least accessible but not inaccessible: lobbying the Council and the European Council. In: COEN, David; RICHARDSON, Jeremy (Eds.). Lobbying the European Union: institutions, actors, and issues. Oxford: Oxford University Press, 2011. p. 70-88 Disponível em: $<$ http://docenti.unimc.it/andrea.prontera/teaching/2016/15964/files/business-lobbying-inthe-european-union_chapter_8_reading_week_3>. Acesso em: 15 mar. 2017.

HEANEY, Michael T.; STRICKLAND, James M. A Network approach to interest groups politics. The Oxford Handbook of Political Networks. New York: Oxford University Press, 2016.

HERNER-KOVÁCS, Eszter. Challenging the Conventional wisdom on ethnic lobby success in the United States: the case of HHRF. Minority Studies, Budapeste, n. 15, p. 199220, 2013. Disponível em: $<$ http://epa.oszk.hu/00400/00463/00015/pdf/EPA00463_minorities_2013-15_199.pdf>.

HILLMAN, Amy J. Determinants of political strategies in U.S. multinationals. Business \& Society, v. 42, n. 4, p. 455-484, Dec. 2003.

; HITT, Michael A. Corporate political strategy formulation: a model of approach, participation, and strategy decisions. Academy of Management Review, v. 24, n. 4, p. 825$842,1999$.

HIND, Rick; KAY, Thomas; VARELA, Kate. 283 Lobbyists led the chemical industry campaign against strong laws and regulations in 2007 (Greenpeace). Washington, May 2008. Disponível em: <http://webcache.googleusercontent .com/search?q=cache:eRkAZPLIvNoJ:research.greenpeaceusa.org/\%3Fa\%3Ddownload\% 26d\%3D4535+\&cd=2\&hl=pt-BR\&ct=clnk\&gl=br>. Acesso em: 28 fev. 2017.

HM GOVERNMENT. Introducing a Statutory Register of Lobbyists. Consultation Paper, Jan. $2012 . \quad$ Disponível em: $<$ https://www.gov.uk/government/uploads/system/uploads/attachment_data/file/78896/Intr oducing_statutory_register_of_lobbyists.pdf $>$. Acesso em: 25 jan. $201 \overline{8}$. 
HOLANDA, Sérgio Buarque de. Raizes do Brasil. São Paulo: Companhia das Letras, 2006.

HOLMAN, Craig. Lobbying reform in the United States and the European Union: progress on two continents. Disponível em: <https://www.citizen.org/documents/Lobbying-Reformin-the-US-EU.pdf>. Acesso em: 04 abr. 2017.

. Making the U.S. Lobbying Disclosure Act Work as intended: implications for the European Transparency Initiative. Disponível em: $<$ https://www.citizen.org/sites/default/files/making-lda-work.pdf $>$. Acesso em: 06 abr. 2017.

. Origins, evolution and structure of the Lobbying Disclosure Act. Disponível em: $<$ http://www.citizen.org/documents/LDAorigins.pdf $>$. Acesso em: 26 fev. 2013; 06 abr. 2017.

HOLMES, Nancy; LITHWICK, Dara. The federal lobbying system: the lobbying act and the lobbyists' Code of Conduct. Library of Parliament Background Papers, n. 2011-73-E, June 2011. Disponível em: $<$ http://www.lop.parl.gc.ca/Content/LOP/ResearchPublications/2011-73-e.pdf $>$. Acesso em: 15 mar. 2017.

HORTON, David. Lobbyists, relationships, and legislators votes. Xaxier Jorunal of Politics, Cincinnati, v. 6, n. 1, p. 72-83, 2015. Disponível em: $<$ https://www.xavier.edu/xjop/documents/XJOPVOLVI2015LobbyistsVotesandRelationsh ips.pdf $>$.

HOUSE OF COMMONS. The Guide to the Rules Relating to the Conduct of Members. London, Apr. $2015 . \quad$ Disponível em: $<$ https://publications.parliament.uk/pa/cm201516/cmcode/1076/1076.pdf $>$.

. Public Administration Select Committee. Lobbying: access and influence in Whitehall: First Report of Session 2008-09. London: The Stationery Office Limited, 2009. v. $1 . \quad$ Disponível em: $<$ https://publications.parliament.uk/pa/cm200809/cmselect/cmpubadm/36/36i.pdf $>$. Acesso em: 18 jan. 2018.

HRABEMAR, Ronaldo; THOMAS, Clive. The rise and fall and rise of the China lobby in the United States. In: CIGLER, Allan J.; LOOMIS, Burdett A. Interest groups politics. 8. ed. Washington: CQPress, 2012.

HUNGRIA, Nelson. Comentários ao Código Penal. 2. ed. Rio de Janeiro: Forense, 1959. v. 9.

IANKOVA, Elena. Business-government relations ins EU-acceding countries: towards a model of institutional change. In: EUSA TENTH BIENNIAL INTERNATIONAL CONFERENCE, Montreal, Canadá May 17-May 19, 2007. Disponível em: $<$ http://aei.pitt.edu/7914/1/iankova\%2De\%2D06d.pdf $>$. 
IANONI, Marcus. O lobby dos Bancos no Brasil: um estudo sobre a FEBRABAN vis à vis o Estado. jul. 2012. Disponível em: <http://www.cienciapolitica.org.br/wpcontent/uploads/2014/04/12_7_2012_17_7_1.pdf>. Acesso em: 15 mar. 2017.

IGAN, Deniz; MISHRA, Prachi; TRESSEL, Thierry. A fistful of dollars: lobbying and the financial crisis. In: ACEMOGLU, Daron; WOODFORD, Michael (Eds.). NBER Macroeconomics Annual 2011. Chicago: University of Chicago Press: 2012. v. 26. p. 195230. (NBER Book Series NBER Macroeconomics Annual). Disponível em: $<$ https://www.nber.org/chapters/c12416.pdf $>$.

INFO LOBBY. Disponível em: <www.infolobby.cl>. Acesso em: 15 jun. 2018.

JACKSON, Brooks. Honest graft: big money and the american political process. New York: Alfred A. Knopf, 1988.

JAREÑO LEAL, Ángeles. Corrupción y delincuencia de los funcionarios en la contratación Pública. Madrid: Iustel, 2011.

JESUS, Damásio de. Crimes de corrupção ativa e tráfico de influência nas transações comerciais internacionais. São Paulo: Saraiva, 2003.

JOBIM, Nelson; SOUZA, Luciano Inácio de. A regulamentação do lobby: análise comparada entre América Latina, Brasil e Estados Unidos. In: SELIGMAN, Milton; MELLO, Fernando (Orgs.). Lobby desvendado: democracia, políticas públicas e corrupção no Brasil contemporâneo. Rio de Janeiro: Record, 2018.

JUDICIÁRIO faz lobby e pressiona governo a aumentar salários da magistratura. Folha de S. Paulo, São Paulo, painel, 29 jun. 2018. Disponível em: $<$ https://painel.blogfolha.uol.com.br/2018/06/29/judiciario-faz-lobby-e-pressiona-governoa-aumentar-salarios-da-magistratura/>. Acesso em: 15 ago. 2018.

JUNQUEIRA, Thais Guimarães. Too big to fail? O fracasso do lobby financeiro na formação das regras para as instituições globais sistematicamente importantes (G-SIBS). 2017. Dissertação (Mestrado) - Instituto de Relações Internacionais da Universidade de São Paulo, São Paulo, 2017.

KARMY, Jorge Sahd; VALENZUELA BUSTOS, Cristián. Lobby law in Chile: democratizing access to public authorities. Disponível em: $<$ https://www.opengovpartnership.org/sites/default/files/case-study_Chile_LobbyLaw.pdf>. Acesso em: 04 fev. 2018.

\section{$\overline{\text { Disponível }}$} . Lobbying regulation in Chile: opening access to authorities. $21 \mathrm{p}$.

$<$ https://www sociedadpoliticaspublicas.cl/archivos/octavo/gestiondeestado/GESTION Sa hd_Jorge.pdf>. Acesso em: 01 fev. 2018.

KINDHÄUSER, Urs. Presupuestos de la corrupción punible en el Estado, la economia y la sociedad. Los delitos de corrupción en el Código Penal alemán. Política Criminal, v. 2, n. 3, p. 1-18, 2007. 
KING, David; POMPER, Miles. The U.S. Congress and the contingent influence of diaspora lobbies: lessons from U.S. policy toward Armenia and Azerbaiajan. Journal of Armenian Studies, v. 8, n. 1, Dec. 2004. Disponível em: $<\mathrm{https}$ ://www.researchgate.net/publication/258910301_David_C_King_Miles_Pomper_Co ngress_and the_Contingent_Influence_of_Diaspora_Lobbies_US_Foreign_Policy_toward _Armenia_Journal_of_Armenian_Studies_December_2004>.

KINGSLEY, Elizabeth. A lobbyist by any other name. Originally published in the journal Taxation of Exempts, v. 20, n. 6, May/June 2009. Disponível em: $<$ http://www.harmoncurran.com/library/BK\%20TOE-Other\%20Name.pdf $>$. Acesso em: 29 jun. 2018.

KLÜVER, Heike. Interest groups influence on EU policy-making: a quantitative analysis across issues. Paper prepared for Presentation at the $11^{\text {th }}$ Biennial Conference of the European Union Studies Association, Los Angeles, 23-25 April 2009. Disponível em: $<$ http://aei.pitt.edu/33094/1/kluever._heike.pdf>. Acesso em: 24 fev. 2018.

Lobbying in coalitions: interest group influence on European Union policymaking. Nuffiel's Working Papers Series in Politics, Oxford, Feb. 2011. Disponível em: $<$ https://www.nuffield.ox.ac.uk/politics/papers/2011/heike\%20kluever_working\%20paper_ 2011_04.pdf>.

. Lobbying in the European Union: interest groups, lobbying coalitions and policy change. Oxford: Oxford University Press, 2013.

KRETSCHMER, Heiko; SCHMEDES, Hans-Jörg. Enhancing transparency in EU lobbying? How the European Commission's lack of courage and determination impedes substantial progress. Internationale Politik und Gesellschft, n. 1, Jan. 2010. Disponível em: $<$ https://library.fes.de/pdf-files/ipg/ipg-2010-1/08_kretschmerschmedes_us.pdf $>$.

KRSMANOVIC, Dusko. A guidebook on lobbying. Belgrado: Konrad Adenauer Stiftung, 2013.

LANGBEIN, Laura I. PACs, lobbies and political conflict: the case of gun control. Public Choice, Holanda, v. 77, p. 551-572, Nov. 1993.

; LOTWIS, Mark A. The political efficacy of lobbying and money: gun control in the U.S. house. Legislative Studies Quaterly, v. 15, n. 3, p. 413-440, Aug. 1990.

LAZZARINI, Sérgio G.; MUSACCHIO, Aldo. O Leviatã nos negócios no Brasil: práticas passadas, mudanças futuras. In: SELIGMAN, Milton; MELLO, Fernando (Orgs.). Lobby desvendado: democracia, políticas públicas e corrupção no Brasil contemporâneo. Rio de Janeiro: Record, 2018.

LEECH, Beth; BAUMGARTNER, Frank; LA PIRA, Timothy; SEMANKO, Nicholas. Drawing lobbyists to Washington: government activity and the demand for advocacy. Political Research Quarterly, v. 58, n. 1, p. 19-30, Mar. 2005. 
LEHMANN, Wilhelm. The European Parliament. In: COEN, David; RICHARDSON, Jeremy (Eds.). Lobbying the European Union: institutions, actors, and issues. Oxford: Oxford University Press, 2011. p. 39-69. Disponível em: $<$ http://docenti.unimc.it/andrea.prontera/teaching/2016/15964/files/business-lobbying-inthe-european-union_chapter_8_reading_week_3>.Acesso em: 15 mar. 2017.

; BOSCHE, Lars. Lobbying in the European Union: current rules and practices. European Parliament, Working Paper, Luxemburgo, 2003. (Constitutional Affairs Series AFCO 104 EN). Disponível em: $<$ http://www.europarl.europa.eu/RegData/etudes/etudes/join/2003/329438/DG-4AFCO_ET(2003)329438_EN.pdf>. Acesso em: 19 fev. 2018.

LEVIANU, Roberto. Controle penal da corrupção. 2004. Tese (Doutorado) - Programa de Pós-Graduação em Direito da Faculdade de Direito, Universidade de São Paulo, São Paulo, 2004.

LEVINE, Carrie. Jack Abramoff is back - as a registered lobbyist. The Center for Public Integrity, June 22, 2017. Disponível em: $<$ https://www.publicintegrity.org/2017/06/22/20942/jack-abramoff-back-registeredlobbyist>. Acesso em: 01 jul. 2017.

'LOBBY' marca estratégia do Ministério Público. Folha de S. Paulo, São Paulo, 23 ago. 1987. Disponível em: $<$ https://www2.senado.leg.br/bdsf/bitstream/handle/id/134264/Agosto\%2087_\%20\%200140.phttps://www2.senado.leg.br/bdsf/bitstream/handle/id/134264/Agosto\%2087_\% 20-\%200140.pdf? sequence=3df? sequence $=3>$. Acesso em: 01 ago. 2018.

LOBBYING Database. Washington, DC., The Center for Responsive Politics (Open Secrets). Disponível em: <https://www.opensecrets.org/lobby/>. Acesso em: 16 maio 2017.

LOBBYING. Washington, DC., The Center for Responsive Politics (Open Secrets). Disponível em: $\quad<$ https://www.opensecrets.org/lobby/top.php?indexType= $1 \&$ show Year=2017>. Acesso em: 16 maio 2017.

LONG, Tony; LÖRINCZI, Larisa. NGOs as gatekeepers: a green vision. In: COEN, David; RICHARDSON, Jeremy (Eds.). Lobbying the European Union: institutions, actors, and issues. Oxford: Oxford University Press, 2011. p. 169-185. Disponível em: $<$ http://docenti.unimc.it/andrea.prontera/teaching/2016/15964/files/business-lobbying-inthe-european-union_chapter_8_reading_week_3>. Acesso em: 15 mar. 2017.

LOOMIS, Burdett A. Learning to Lobby: groups, venues, and information in eighteenthcentury America. In: CIGLER, Allan J.; LOOMIS, Burdett A. (Eds.). Interest groups politics. 8. ed. Washington: CQPress, 2012.

; CIGLER, Allan J. Introduction: The changing nature of interest group politics. In: CIGLER, Allan J.; LOOMIS, Burdett A. (Eds.). Interest groups politics. 8. ed. Washington: CQPress, 2012. 
LOPES, José Mouraz. Sobre o novo crime de tráfico de influência: artigo $335^{\circ}$ do Código Penal. Revista do Ministério Público de Lisboa, v. 16, n. 64, p. 55-65, out./dez. 1995.

LORD, Michael D. Corporate political strategy and legislative deicion making: the impact of corporate legislative influence activities. Business Society, v. 39, n. 1, p. 76-93, Mar. 2000 .

LORENZI, Maximiliano. Consultants in the European Union: strategizing for opportunities. beyond lobbying: the strategies carried out with the large firms, Amsterdã, Feb. 2005.2 Disponível em: $<$ https://www.academia.edu/4581779/Consultants_in_the_European_Union_strategizing_f or_opportunities._Beyond_lobbying_the_strategies_carried_out_with_the_large_firms $>$. Acesso em: 15 mar. 2017.

LOWERY, Daniel. Why do organized interests lobby? Leiden: Unisersiteit Leiden Editor, 2005. Disponível em: <https://openaccess.leidenuniv.nl/handle/1887/3492>. Acesso em: 22 abr. 2017.

LUNEBURG, Willian V. The evolution of Federal Lobbying Regulation: where we are now and where we should be going. McGeorge Law Review, v. 41, p. 85-130, 2009. Disponível em: $<$ https://www.mcgeorge.edu/Documents/Publications/MLR4104_Luneburg_MASTER.pdf $>$. Acesso em: 01 jul. 2017.

MAHONEY, Christine. Lobbying success in the United States and the European Union. Journal of Public Policy, Cambridge, n. 27, v. 1, p. 35-56, 2007.

MALONE, Margaret May. Regulation of lobbying in developed countries: current rules and practices. Institute of Public Administration. Disponível em: $<$ https://www.housing.gov.ie/sites/default/files/migrated-

files/en/Publications/LocalGovernment/Administration/FileDownLoad\%2C2048\%2Cen.pd f>. Disponível em: 09 abr. 2017.

MANCUSO, Wagner Pralon; ANGÉLICO, Fabiano; GOZETTO, Andrea Cristina. Ferramentas de transparência: o possível impacto da Lei de Acesso a Informações Públicas no debate sobre regulamentação do lobby no Brasil. Revista de Informação Legislativa, RIL, Brasília, ano 52, n. 212, p. 41-56, out./dez. 2016. Disponível em: $<$ https://www12.senado.leg.br/ril/edicoes/53/212/ril_v53_n212_p41.pdf $>$. Acesso em: 06 maio 2017.

MARTÍNEZ GALINDO, Gema. El delito de tráfico de influencias en la administración local. La Ley Penal: revista de derecho penal, procesal y penitenciário, v. 2, n. 22, p. 36$50,2005$.

MASKELL, Jack. Lobbying Congress: an overview of legal provisions and congressional ethics rules. Congressional Research Service Report, Oct. 2007. Disponível em: $<$ https://fas.org/sgp/crs/misc/RL31126.pdf>. Acesso em: 06 maio 2017. 
MATELLANES RODRÍGUEZ, Nuria. El delito de cohecho de funcionarios nacionales: condicionantes internacionales y principales aspectos de su nueva regulación en el Código Penal español. Revista Brasileira de Ciências Criminais, São Paulo, v. 19, n. 89, p. 355385, mar./abr. 2011.

MCCOWN, Margaret. Interest groups and the European Court of Justice. In: COEN, David; RICHARDSON, Jeremy (Eds.). Lobbying the European Union: institutions, actors, and issues. Oxford: Oxford University Press, 2011. p. 89-104. Disponível em: $<$ http://docenti.unimc.it/andrea.prontera/teaching/2016/15964/files/business-lobbying-inthe-european-union_chapter_8_reading_week_3>.Acesso em: 15 mar. 2017.

MCGRATH, Conor. The development and regulation of lobbying in the new Member States of the European Union. Journal of Public Affairs, n. 8, p. 15-32, 2008. Disponível em: $<$ http://lobbyists.ru/eu/11.pdf $>$.

MEARSHEIMER, John J.; WALT, Stephen M. The Israel lobby and U.S. foreign policy. Middle East Policy Council, v. 13, n. 3, 2006.

MEDAUAR, Odete. Direito administrativo moderno. 12. ed. São Paulo: Revista dos Tribunais, 2008.

MELLADO-BERMEJO, Lucia; PARTE ESTEBAN, Laura. An exploratory study of participation intensity in comment-letters: lease accounting proposal. Disponível em: $<$ http://www.aeca1.org/pub/on_line/comunicaciones_xviencuentroaeca/cd/59a.pdf $>$. Acesso em: 15 mar. 2017.

MELLO, Sebastián Borges de Albuquerque. O sujeito ativo do tráfico de influência e o Anteprojeto do novo Código Penal. Revista Brasileira de Ciências Criminais, São Paulo, v. 22, n. 110, p. 125-144, set./out. 2014.

MELO, Carlos. Relações governamentais: significado, funcionamento e problemas da democracia no Brasil. In: SELIGMAN, Milton; MELLO, Fernando (Org.). Lobby desvendado: democracia, políticas públicas e corrupção no Brasil contemporâneo. Rio de Janeiro: Record, 2018.

MEYER-PFLUG, Samantha Ribeiro (Coord. Acad.). Grupos de interesse (lobby). BrasíliaDF: Secretaria de Assuntos Legislativos do Ministério da Justiça (SAL), 2009. (Série Pensando o Direito, n. 8/2009). Disponível em: <http://pensando.mj.gov.br/wpcontent/uploads/2015/07/08Pensando_Direito1.pdf>. Acesso em: 15 out. 2018.

MICHIGAN DEPARTMENT OF STATE BUREAU OF ELECTIONS. Lobby manual: Michigan Lobby Registration Act. Michigan, Dec. 2015.

MIHUT, Liliana. Lobbying in the United States and the European Union: new developments in lobbying regulation. Romanian Journal of European Affairs, v. 8, n. 4, p. 5-17, Nov. 2008. Disponível em: $<$ http://beta.ier.ro/documente/rjea_vol8_no4/RJEA_Vol8_No4_Lobbying_in_the_United_ States_and_the_European_Union_New_Developments_in_Lobbying_Regulation.pdf $>$. Acesso em: 02 ago. 2017. 
MILBRATH, Lester W. The Washington lobbyists. Chicago: Rand McNally \& Company, 1963.

MILLER, David; HARKINS, Claire. Corporte strategy, corporate captude: food and alcohol industry lobbying and public health. Critical Social Policy, v. 30, n. 4, p. 564-589, 2010 .

MINISTÉRIO DO TRABALHO E EMPREGO. Classificação Brasileira de Ocupações: CBO - 2010. 3.ed. Brasília-DF: MTE, SPPE, 2010. Disponível em: $<$ http://www.cofen.gov.br/wpcontent/uploads/2015/12/CLASSIFICA\%C3\%87\%C3\%83O-BRASILEIRA-DEOCUPA\%C3\%87\%C3\%95ES-MEC.pdf>. Acesso em: 15 mar. 2017.

MOHALLEM, Michael Freitas et al. Novas medidas contra a corrupção. Rio de Janeiro: Escola de Direito do Rio de Janeiro da Fundação Getúlio Vargas, 2018. Disponível em: $<$ https://unidoscontraacorrupcao.org.br/assets/pdf/Novas_Medidas_pacote_completo.pdf $>$. Acesso em: 22 mar. 2018.

MUÑOZ CONDE, Francisco. Derecho penal: parte especial. 19. ed. Valencia: Tirant lo Blanch, 2013.

NEWHOUSE, John. Diplomacy, Inc.: the influence of lobbies on U.S. Foreign Policy. Foreing Affairs, v. 88, n. 3, p. 73-92, May/June 2009.

NIETO MARTÍN, Adán. Conflicto de intereses y transparencia. In: ARROYO ZAPATERO, Luis; NIETO MARTÍN, Adán (Coords.). Fraude y corrupción en el derecho penal económico europeu: eurodelitos de corrupción y fraude. Cuenca: Ediciones de la Universidad Castilla-la Mancha, 2006. p. 113-116.

NÓBREGA, Mailson da. O lobby dos servidores contra a reforma da Previdência. Blog Mailson da Nóbrega, 18 dez. 2017. Disponível em: $<$ https://veja.abril.com.br/blog/mailson-da-nobrega/o-lobby-dos-servidores-contra-areforma-da-previdencia>. Acesso em: 15 jan. 2018.

NORONHA, Magalhães. Direito penal. 1. ed. São Paulo: Saraiva, 1978. v. 4.

NOWNES. Anthony. Total lobbying: what lobbyists want (and how they try to get it). New York: Cambridge University Press, 2006.

OBRADOVIC, Daniela. Regulating lobbying in the European Union. In: COEN, David; RICHARDSON, Jeremy (Eds.). Lobbying the European Union: institutions, actors, and issues. Oxford: Oxford University Press, 2011. p. 298-334. Disponível em: $<$ http://docenti.unimc.it/andrea.prontera/teaching/2016/15964/files/business-lobbying-inthe-european-union_chapter_8_reading_week_3>. Acesso em: 15 mar. 2017.

OCDE. ORGANISATION FOR ECONOMIC CO-OPERATION AND DEVELOPMENT. (The CleanGovBiz Initiative). Lobbying: influencing decision making with transparency and integrity. July 2012. Disponível em: $<$ http://www.oecd.org/cleangovbiz/toolkit/50101671.pdf>. Acesso em: 26 mar. 2018. 
OCDE. ORGANISATION FOR ECONOMIC CO-OPERATION AND DEVELOPMENT.

Lobbyists, government and public trust: increasing transparency through legislation. Paris: OECD $2009 . \quad$ vublishing, $1 . \quad$ Disponível em: $<$ http://www.oecd.org/publications/lobbyists-governments-and-public-trust-volume-19789264073371-en.htm>. Acesso em: 27 mar. 2018.

Lobbyists, government and public trust: increasing transparency through legislation. Paris: OECD Publishing, 2010. v. 2. Disponível em: <https://www.oecdilibrary.org/lobbyists-governments-and-public-trust-volume-

2_5kmjpnlc8h6j.pdf?itemId=\%2Fcontent\%2Fpublication $\% 2 F 9789264084940$ en\&mimeType $=$ pdf $>$. Acesso em: 08 abr. 2018.

- Lobbyists, Government and public trust: increasing transparency through legislation. Paris: OECD Publishing, 2014. v. 3. Disponível em: $<$ http://www.oecd.org/fr/corruption/lobbyists-governments-and-public-trust-volume-39789264214224-en.htm>. Acesso em: 10 abr. 2018.

. Recomendação do Conselho da OCDE sobre Integridade Pública. Disponível em: $\overline{<\mathrm{http}: / / w w w . o e c d . o r g / g o v / e t h i c s / i n t e g r i t y-r e c o m m e n d a t i o n-b r a z i l i a n-p o r t u g u e s e . p d f ~}>$. Acesso em: 19 set. 2018.

OFFICE OF THE LEGISLATIVE INSPECTOR GENERAL. Ohio Lobbying Handbook (2014). Disponível em: $\quad<$ http://www.jlecolig.state.oh.us/PDFs/nLobbying/Ohio\%20Lobbying\%20Handbook.pdf $>$. Acesso em: 15 mar. 2017.

OFFICE OF THE REGISTRAR OF CONSULTANT LOBBYISTS. Guidance on compliance with the Register of Consultant Lobbyists. July 2015. Disponivel em: $<$ http://registrarofconsultantlobbyists.org.uk/wp-content/uploads/2015/12/20150723Guidance-on-compliance.pdf $>$. Acesso em: 27 jan. 2018.

OLIVEIRA, Andrea Cristina de Jesus. Breve histórico sobre o desenvolvimento do lobbying no Brasil. Revista de Informação Legislativa, RIL, Brasília, ano 42, n. 168, p. 2944, out./dez. 2005. Disponível em: $<$ https://www12.senado.leg.br/ril/edicoes/42/168/ril_v42_n168_p29.pdf >. Acesso em: 15 mar. 2017.

OPHEIM, Cynthia. Explaining the differences in State lobby Regulation. The Western Political Quarterly, v. 44, n. 2, p. 405-421, June 1991.

ORTIZ DE URBINA GIMENO, Iñigo. Delitos contra la administración pública. In: SILVA SÁNCHEZ, Jesús-Maria (Dir.); RAGUÉS VALLÈS, Ramon (Coord.) Lecciones de derecho penal: parte especial. 3. ed. Barcelona: Atelier Libros Jurídicos, 2011.

PAGLIARO, Antonio. Principi di diritto penale: parte speciale (delitti contro la pubblica amministrazione). 8. ed. Milano: Giuffrè, 1998. 
PARLIAMENT (UK). Transparency of lobbying, non-party campaigning and trade union Administration Act 2014. Chapter 4. The Stationery Office, Reino Unido, 2014. Explanatory Notes. Disponível em: <www.legislation.gov.uk/ukpga/2014/4/contents/enacted>. Acesso em: 25 jan. 2018.

PARVIN, Philip. Fried or foe: lobbying in british democracy. London: Hansard Society, 2007.

PEDRAZZI, Cesare. Millantato credito, trafic d'influence, influence peddling. Rivista Italiana di Diritto e Procedura Penale, Milano, v. 11, n. 4, 1968.

PEDROSO, Vanessa Alessandra de Melo. O bem jurídico protegido e sua aplicação no delito de tráfico de influência. Revista da Escola Superior da Magistratura de Pernambuco, Recife, v. 13, n. 27, p. 573-598, jan./jun. 2008.

PERDIGÃO, Carlos Frederico Marques. Manual do Código Penal brasileiro: estudos syntheticos e práticos. Rio de Janeiro: D.L. Garnier, 1882.

PEREIRA, Pablo; ALMEIDA, Neila; OLIVEIRA, Paulo. Agronegócio tem a bancada mais bem organizada do Congresso. UOL Últimas Notícias (Estadão Conteúdo), São Paulo, 29 jul. 2018. Disponível em: <https://noticias.uol.com.br/ultimas-noticias/agenciaestado/2018/07/29/agronegocio-tem-a-bancada-mais-bem-organizada-do-congresso.htm>. Acesso em: 16 set. 2018.

PORTER, Roger B. Government-business relations in the United States. In: TRANSATLANTIC perspectives on US-EU economic relations: convergence, conflict and cooperation. Boston, Apr. 8, 2002. Disponível em: <https://sites.hks.harvard.edu/mrcbg/Conferences/us-eu_relations/porter_government_business.pdf $>$.

PORTUGAL. Código Penal Português. Disponível em: $<$ https://www.unifr.ch/ddp1/derechopenal/legislacion/1_20080626_10.pdf >. Acesso em: 16 set. 2018.

POWELL, Eleanor Neff. Money and internal influence in Congress. June 10, 2016. Disponível em: $<$ http://www.scholarsstrategynetwork.org/sites/default/files/powell_money_and_internal_i nfluence in congress.pdf $>$. Acesso em: 27 fev. 2017.

PRADO, Luiz Régis. Curso de direito penal brasileiro: parte especial. São Paulo: Revista dos Tribunais, 2001. v. 4.

A Lei 10.467/2002 e os novos crimes de corrupção e tráfico de influência internacional. Revista dos Tribunais, São Paulo, v. 91, n. 803, p. 441-458, set. 2002.

PROSDOCIMI, Salvatore. In tema di illecita influenza sulla formazione della maggioranza assembleare: l'oggetto della tutela. Rivista Italiana di Diritto e Procedura Penale, Milano, v. 20, n. 2, p. 600-634, 1977. 
PROSS, Paul A. Lobbying models for regulation. OECD Paper, 07-May-2007. Disponível em:

$<$ http://www.oecd.org/officialdocuments/publicdisplaydocumentpdf/?cote=GOV/PGC/ET $\mathrm{H}(2007) 4 \&$ docLanguage=En>. Acesso em: 28 jan. 2018.

. The Lobbyists Registration Act: its application and effectiveness. In: Restoring accountability - research studies: volume 2 - The Public Service and transparency. John H. Gomery, Commissioner. Ottawa - Ontario: Privy Council 2006. p. 163-231. Disponível em: $<$ https://www.cbc.ca/news2/background/groupaction/v2fullreport/CISPAA_Vol2_5.pdf $>$. Acesso em: 28 maio 2017.

PUBLIC AFFAIRS BOARD. The Register. Disponível em: $<$ https://www.appc.org.uk/register/>. Acesso em: 27 jan. 2018.

PUBLIC RELATIONS CONSULTANTS ASSOCIATION (PRCA). Disponível em: $<$ https://www.prca.org.uk>. Acesso em: 27 jan. 2018.

. Professional Charter and Codes of Conduct. Disponível em: $<$ https://www.prca.org.uk/about-us/pr-standards/professional-charter-and-codes-conduct $>$. Acesso em: 27 jan. 2018.

. Public Affairs Register. Disponível em: <https://www.prca.org.uk/about-us/prstandards/public-affairs-register $>$. Acesso em: 27 jan. 2018.

RAMIREZ, Rodrigo; STERNSDORFF, Nicole; PASTOR, Carolina. Lobby in Chile: do we have the law we need? Special Report, Santiago de Chile, Feb. 2016. Disponível em: $<$ https://www.desarrollando-ideas.com/wp-

content/uploads/sites/5/2016/02/160217_DI_report_lobby_Chile_ENG.pdf $>$. Acesso em: 04 fev. 2018.

RASMUSEN, Eric. Lobbying when the decisionmaker can acquire independent information. Public Choice, v. 77, n. 4, p. 899-913, Dec. 1993.

RASMUSSEN, Maja Kluger. Lobbying the European Parliament: a necessary evil. CEPS Policy Brief, n. 242, p. 1-6, May 2011. Disponível em: $<$ http://aei.pitt.edu/31864/1/No_242_Rasmussen_on_EP_Lobbying_final.pdf $>$.

REALE JÚNIOR, Miguel. Dever de lealdade do administrador da empresa no Direito Penal. In: REALE, Miguel; REALE JÚNIOR, Miguel; REALE FERRARI, Eduardo (Orgs.). Experiências do direito. Campinas: Millennium, 2004.

REHR, David. The honest leadership and Open Government Act: five years later: a review of the impact of lobbying's most sweeping ethics law. Washington: George Washington University, 2012. Disponível em: <http://legaltimes.typepad.com/files/hloga_report.pdf >. Acesso em: 23 abr. 2017.

RIBEIRO, Pedro Feliú. Comportamento legislativo e politica externa na América Latina. 2012. Tese (Doutorado) - Faculdade de Filosofia, Letras e Ciências Humanas da Universidade de São Paulo, São Paulo, 2012. 
RICHARDSON, Jeremy J. Government, interest groups and policy change. Political Studies, v. 48, n. 5, p. 1006-1025, Feb. 2000. Disponível em: $<$ https://www.researchgate.net/profile/Jeremy_Richardson3/publication/4779866_Govern ment_Interest_Groups_and_Policy_Change/links/59e7a32fa6fdccfe7f8aea9f/GovernmentInterest-Groups-and-Policy-Change.pdf $>$.

; JORDAN, A. G. Governing under pressure: the policy process in a postparliamentary democracy. Oxford: Basil Blackwell, 1982.

RIZZO, Alana; VELASCO, Joel. As empresas conseguem migrar do crony capitalism para práticas íntegras de interação com o governo? In: SELIGMAN, Milton; MELLO, Fernando (Orgs.). Lobby desvendado: democracia, políticas públicas e corrupção no Brasil contemporâneo. Rio de Janeiro: Record, 2018.

RIZZO, Carmelo. Brevi considerazioni sul "traffico di influenze illecite". Rivista Trimetrale di Diritto Penale dell'Economia, ano 30, n. 1-2, p. 166-186, 2017.

ROBINS, Rand. Why the Honest Leadership and Open Government Act of 2007 falls short, and how it could be improved. Legislation and Policy Brief, v. 2, n. 2, Article 4, p. 1-25, 2010.2 Disponível em: $<$ https://digitalcommons.wcl.american.edu/cgi/viewcontent.cgi?article $=1015 \&$ context $=1 p b$ >. Acesso em: 26 fev. 2017.

RODRIGUES, Ricardo José Pereira. A Regulamentação do lobby em países selecionados da Europa. Consultoria Legislativa da Câmara dos Deputados, dez. 2011.

RODRÍGUEZ, Víctor Gabriel. Crimes cometidos pelo particular contra a Administração. In: REALE JÚNIOR, Miguel (Org.). Direito penal: jurisprudência em debate. Rio de Janeiro: GZ, 2013. v. 4.

. Dos crimes praticados por particular contra a Administração em geral. In: REALE

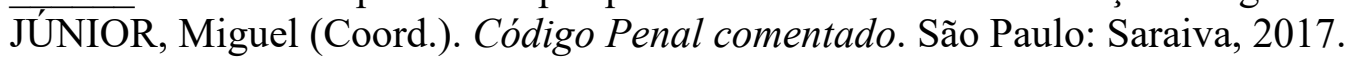

. Tráfico de influência. In: REALE JÚNIOR, Miguel (Coord.). Código Penal comentado. São Paulo: Saraiva, 2017.

ROMANO, Mario. Legge anticorruzione, millantato credito e traffico di influenze illecite. Rivista Italiana di Diritto e Procedura Penale, Milano, ano 56, n. 3, giul./ set. 2013.

ROSAS OLIVA, Juan Ignacio. Consideraciones para la tipificación de un delito contra la corrupción en el sector privado en España. Cuadernos de Política Criminal, Madrid, n. 99, p. $93-123,2009$.

ROSEN, Keith S. The Jeito: Brasil's institutional by-pass of the formal legal system and its developmental implications. The American Journal of Comparative Law, v. 19, n. 3, p. 514-549, 1971.

ROSENTHAL, Alan. The third house: lobbyists and lobbying in the States. 2. ed. Washington: Congressional Quarterly Press, 2001. 
RUDENKOVA, Daria. Interest representation: can Lobbying Regulation help eu overcome democratic defict? Disponível em: <http://euroacademia.eu/wordpress/wpcontent/uploads/2014/11/Daria_Rudenkova_Interest_Representation_-

Can_Lobbying_Regulation_Help_EU_Overcome_Democratic_Deficit.pdf $>$. Acesso em: $26 \mathrm{fev} .2017$.

SALISBURY, Robert H. An exchange theory of interest groups. Midwest Journal of Political Science, v. 13, n.1, p. 1-32, Feb. 1969. Disponível em: $<$ http://pavroz.ru/files/salisburyexchangetheory.pdf $>$.

SANSON, Alexandre. Dos grupos de pressão na democracia representativa: os limites jurídicos. 2013. Tese (Doutorado) - Programa de Pós-Graduação em Direito da Faculdade de Direito da Universidade de São Paulo, São Paulo, 2013.

SANTOS, Luiz Alberto dos. Regulação do lobby no Brasil: o Projeto de Lei ${ }^{0} 1.202$, de 2007 - constitucionalidade e adequação aos fins pretendidos. Interesse Público, Belo Horizonte, ano 14, n. 72, mar./abr. 2012.

. Regulamentação das atividades de lobby e seu impacto sobre as relações entre politicos, burocratas e grupos de interesse no ciclo de politicas públicas: análise comparativa dos Estados Unidos e Brasil. Brasília-DF: Ed. do Senado Federal, 2007.

SAURUGGER, Sabine. Interest groups and democracy in the European Union. West European Politics, v. 31, n. 6, p. 1274-1291, Nov. 2008. Disponível em: $<$ https://www.researchgate.net/profile/Sabine_Saurugger/publication/248944331_Interest_ Groups_and_Democracy_in_the_European_Union/links/56e4569308ae65dd4cbe 7c1d/Inte rest-Groups-and-Democracy-in-the-European-Union.pdf>. Acesso em: 24 mar. 2017.

; COREPER and National Governments. In: COEN, David; RICHARDSON, Jeremy (Eds.). Lobbying the European Union: institutions, actors, and issues. Oxford: Oxford University Press, 2011. p. 105-127. Disponível em: $<$ http://docenti.unimc.it/andrea.prontera/teaching/2016/15964/files/business-lobbying-inthe-european-union_chapter_8_reading_week_3>. Acesso em: 15 mar. 2017.

SCHNEIDER, Anne L.; INGRAM, Hellen. Policy design for democracy. Lawrence: University Press of Kansas, 1997. Paperback. (Studies in Government and Public Policy Series).

SCOTLAND (UK). Lobbying (Scotland) Act 2016 (asp 16). Disponível em: $<$ https://www.legislation.gov.uk/asp/2016/16/pdfs/asp_20160016_en.pdf $>$. Acesso em: 28 jan. 2018.

SEDRAKYAN, Artyon. The armenian lobby and U.S. foreign policy. p. 57-64. Disponível em: <http://ysu.am/files/06A_Sedrakyan.pdf>. Acesso em: 15 mar. 2017.

SELIGMAN, Milton; BANDEIRA, Mateus Affonso. Manual de melhores práticas em relações institucionais. In: SELIGMAN, Milton; MELLO, Fernando (Orgs.). Lobby desvendado: democracia, políticas públicas e corrupção no Brasil contemporâneo. Rio de Janeiro: Record, 2018. 
SELIGMAN, Milton; MELLO, Fernando (Orgs.). Lobby desvendado: democracia, políticas públicas e corrupção no Brasil contemporâneo. Rio de Janeiro: Record, 2018.

SENATE. Lobbying Disclosure Act Guidance. Effective January 1, 2008. Reviewed January 31, 2017/Last Revised January 31, 2017. Disponível em: $<$ https://lobbyingdisclosure.house.gov/ldaguidance.pdf $>$. Acesso em: 04 abr. 2017 e 16 jan. 2018.

SILVA, Carlos José Santos da. A regulamentação do lobby no Brasil. Revista Brasileira da Advocacia, ano 2, v. 5, p. 19-32, abr./jun. 2007.

SLOOT Huub; GANNDERSE, Mariken. Guidelines on lobbying and advocacy. ICCO Partner to Enterprising People, June 2010. Disponível em: <http://www.ealliance.ch/fileadmin/user_upload/docs/Advocacy_Capacity/2011/8.ICCO_Guidelines_on _Lobby_and_Advocacy_2010.pdf >.

SMITH, Richard. Interest group influence in the U.S. Congress. Legislative Studies Quaterly, v. 20, n. 1, p. 89-139, Feb. 1995.

SOLOWIEJ, Lisa A.; COLLINS JR., Paul M. Counteractive lobbying in the U.S. Supreme Court. American Politics Research, v. 37, n. 4, p. 670-699, June 2009.

SOTERO, Paulo; PRUSA, Anna C. O lobby nos EUA: a transparência de um sistema imperfeito. In: SELIGMAN, Milton; MELLO, Fernando (Orgs.). Lobby desvendado: democracia, políticas públicas e corrupção no Brasil contemporâneo. Rio de Janeiro: Record, 2018.

SOUZA, Luciano Anderson de. Crimes contra a administração pública. São Paulo: Revista dos Tribunais, 2018.

SPENA, Alessandro. Punire la corruzione privata? Un inventario di perplessità políticocriminali. Rivista Trimestrale di Diritto Penale Dell'Economia, Milano, ano 20, n. 4, ott./dic. 2007.

STEFAN, Oanta Ilie; NICOLETA, Vasilcoschi. The business fluctuations and the lobbying evolution in European Union, Canada and USA. The Romanian Economic Journal, ano 18, n. 55, p. 163-174, Mar. 2015. Disponível em: $<\mathrm{http}: / / w w w . r e j o u r n a l . e u / s i t e s /$ rejournal.versatech.ro/files/articole/2015-0318/3251/yoanta.pdf>. Acesso em: 24 mar. 2017.

STOCKER, Tim; GRANT, Wyn. Politics of food: agro-industry lobbying in Brussels. In: COEN, David; RICHARDSON, Jeremy (Eds.). Lobbying the European Union: institutions, actors, and issues. Oxford: Oxford University Press, 2011. p. 233-255. Disponível em: $<$ http://docenti.unimc.it/andrea.prontera/teaching/2016/15964/files/business-lobbying-inthe-european-union_chapter_8_reading_week_3 >. Acesso em: 15 mar. 2017. 
STRAUS, Jacob R. Honest Leadership and Open Government Act of 2007: the role of the clerk and of the House and secretary of the Senate. Congressional Research Service Report, Apr. 2017. Disponível em: <https://www.senate.gov/CRSpubs/63879f94-69664341-9342-03ab6d8bff33.pdf>. Acesso em: 23 abr. 2017.

The Lobbying Disclosure Act at 20: analysis and issues for Congress. Congressional Research Service Report, Dec. 2015. Disponível em: $<$ https://fas.org/sgp/crs/misc/R44292.pdf>. Acesso em: 15 mar. 2017.

TANSEY, Rachel. Fracking Brussels: a who's who of the EU shale gas lobby. Bruxelas: Friends of the Earth Europe, 2014.

TAVARES, Bruno; LEITE, Isabela. Polícia Federal faz operação contra desvio recursos da União para merenda em 3 Estados e no DF. Gl, 09 maio 2018. Disponível em: $<$ https://g1.globo.com/sp/sao-paulo/noticia/policia-federal-faz-operacao-contra-desvio-dedinheiro-publico.ghtml>. Acesso em: 10 out. 2018.

TAYLOR, Matthew M. A corrupção e as reformas anticorrupção no Brasil. In: SELIGMAN, Milton; MELlO, Fernando (Orgs.). Lobby desvendado: democracia, políticas públicas e corrupção no Brasil contemporâneo. Rio de Janeiro: Record, 2018.

TEIXEIRA, Luiz Fernando; MACEDO, Fausto. Lobista do MDB pede habeas. Estadão, 16 abr. 2018. Disponível em: <https://politica.estadao.com.br/blogs/fausto-macedo/lobistado-mdb-pede-habeas//>. Acesso em: 10 out. 2018.

TEMER mandou lobista da JBS entregar R\$ 3 milhões de propina a Eduardo Cunha, diz Época. Congresso em Foco, 01 ago. 2017. Disponível em: $<$ https://congressoemfoco.uol.com.br/especial/noticias/temer-mandou-lobista-da-jbsentregar-r-3-milhoes-de-propina-a-eduardo-cunha-diz-revista/>. Acesso em: 23 fev. 2018.

THIEL, Marie; BAUER, Elisabeth. EU Transparency Register. EPRS European Parliamentary Research Service, May 2016. Disponível em: $<$ http://www.europarl.europa.eu/EPRS/EPRS-Briefing-542170-European-TransparencyRegister-FINAL.pdf>. Acesso em: 24 fev. 2018.

THOMAS, Clive S. Interest group regulation across the United States: rationale, development and consequences. Parliamentary Affairs, v. 51, n. 4, p. 500-515, Oct. 1998.

TILBURG, Rens Vans; RÖMGENS, Indra. Taking Lobbying Public: the transparency of Dutch Bank's lobbying activities. The Netherlands: Stichting Onderzoek Multinationale Ondernemingen (SOMO) / Centre for Research on Multinational Corporations, Dec. 2013. Disponível em: $<$ https://www.somo.nl/wp-content/uploads/2013/12/Taking-LobbyingPublic-1.pdf>. Acesso em: 15 mar. 2017.

TRANSPARENNCIA INTERNACIONAL. Chile Transparente. Manual Ley $n^{\circ} 20.730$. Disponível em: <http://www.chiletransparente.cl/wp-content/uploads/2013/03/ManualLobby-Municipalidades-FINAL.pdf>. Acesso em: 07 abr. 2017. 
TRANSPARENCY INTERNATIONAL. Corruption Perceptions Index 2016. 25 Jan. 2017. Disponível em: $<$ https://www.transparency.org/news/feature/corruption_perceptions_index_2016\#table>. Acesso em: 01 jul. 2017.

ESPAÑA. La falta de regulación del lobby en Europa favorece la corrupción. Berlín, Apr. 2015.

EU Integrity Watch Brussels lobbying in numbers. Brussels, June 2015.

. EU OFFICE. 7,000 and counting: lobbying meetings of the European Commission. Brussels, Dec. 2015. Disponível em: <https://transparency.eu/wpcontent/uploads/2016/10/Lobby-Meetings-European-Commission.pdf $>$.

. Money, politics, power: corruption risks in Europe. Berlin: Transparency International. International Secretariat, 2012. Disponível em: $<$ https://www.transparency.org/whatwedo/publication/money_politics_and_power_corrupt ion_risks_in_europe $>$. Acesso em: 24 fev., 19 maio 2018.

TREIB, Oliver; FALKNER, Gerda. Bargaining and lobbying in the EU social policy. In: COEN, David; RICHARDSON, Jeremy (Eds.). Lobbying the European Union: institutions, actors, and issues. Oxford: Oxford University Press, 2011. p. 256-276. Disponível em: $<$ http://docenti.unimc.it/andrea.prontera/teaching/2016/15964/files/business-lobbying-inthe-european-union_chapter_8_reading_week_3 >. Acesso em: 15 mar. 2017.

UBER, Cabify e 99 criam campanha contra projeto de lei que inviabiliza serviços. 25 set. 2017. Disponível em: <https://canaltech.com.br/governo/uber-cabify-e-99-criam-campanhacontra-projeto-de-lei-que-inviabiliza-servicos-100934>. Acesso em: 16 jul. 2018.

UNIÃO EUROPEIA. Os 28 países da EU. Disponível em: <https://europa.eu/europeanunion/about-eu/countries_pt>. Acesso em: 18 abr. 2017.

UNITED STATES GENERAL ACCOUNTING OFFICE. Federal Regulation on Lobbying Act of 1946 is ineffective (Statement of Milton J. Scolar), 16 July 1991. Disponível em: <http://www.gao.gov/assets/110/104007.pdf> Acesso em: 06 maio 2017.

UNITED States v. Harriss - 347 U.S. 612, 74 S.Ct. 808, 98 L.Ed. 989 (1954). Disponível em: $<$ https://www.princeton.edu/aci/cases-pdf/aci1.harriss.pdf $>$. Acesso em 18 jun. 2017.

U.S. CONGRESS. House Committee on the Judiciary. Lobbying Disclosure Act of 1995. Report to accompany H.R. 2564, 104th Congress, 1ª Sessão: Washington, 1995.

VÉRON, Michel. Droit pénal spécial. 14. ed. Paris: Dalloz, 2012.

VICTOR, Jennifer. Gridlock lobbying: breaking, creating and maintaining legislative stalemate. In: CIGLER, Allan J.; LOOMIS, Burdett A. Interest groups politics. 8. ed. Washington: CQPress, 2012. 
VIDACAK, Igor. Interest groups and lobbying in the European Union. Croatian International Relations Review, v. 9, n. 33, p. 177-188, Oct./Dec. 2003. Disponível em: $<$ https://hrcak.srce.hr/file/181369>. Acesso em: 18 jun. 2017.

VIEIRA, André Guilherme; DI CUNTO, Raphael. PF realiza operação contra fraude milionária em registros sindicais. Valor Econômico, 30 maio 2018. Disponível em: $<$ https://www.valor.com.br/politica/5559437/pf-realiza-operacao-contra-fraude-milionariaem-registros-sindicais>. Acesso em 15 jun. 2018.

WAGREICH, Samuel. Lobbying by Proxy: a study of China's lobbying practices in the United States 1979-2010 and the implications for Fara. Journal of Politics \& Society, v. 24, n. 1, p. 130-160, Mar. 2013. Disponível em: $<$ https://academiccommons.columbia.edu/doi/10.7916/D85M6GV2/download $>$.

WARDE JÚNIOR, Walfrido Jorge. A empresa pluridimensional: empresa política e lobby. Revista do Advogado, São Paulo, v. 28, n. 96, p. 137-145, mar. 2008.

WARHURST, John. Locating the target: regulating lobbying in Australia. Parliamentary Affairs, v. 51, n. 4, p. 538-550, Oct. 1998.

WEBB, Philippa. The United Nations Convention Against Corruption: global achievement or missed opportunity? Journal of International Economic Law, Oxford, v. 8, n. 1, p. 191229, 2005. Disponível em: $<$ https://papers.ssrn.com/sol3/Delivery.cfm/SSRN_ID2557193_code2192959.pdf?abstracti $\mathrm{d}=2557193 \&$ mirid=1>. Acesso em: 19 nov. 2018 .

WESTLAKE, Martin. The European Economic and Social Committee. In: COEN, David; RICHARDSON, Jeremy (Eds.). Lobbying the European Union: institutions, actors, and issues. Oxford: Oxford University Press, 2011. p. 128-142. Disponível em: $<$ http://docenti.unimc.it/andrea.prontera/teaching/2016/15964/files/business-lobbying-inthe-european-union_chapter_8_reading_week_3>. Acesso em: 15 mar. 2017.

WOLL, Cornelia. Lobbying in the European Union: from sui generis to a comparative perspective. Journal of European Public Policy, v. 13, n. 3, p. 456-470, 2006. Disponível em: $<$ https://hal-sciencespo.archives-ouvertes.fr/hal-01021182/document $>$. Acesso em: 08 mar. 2017.

WOLPE, Bruce C.; LEVINE, Bertam J. Lobbying congress: how the system works. 2. ed. Washington: CQPress, 1996.

WOLTON, Stephane. Lobbying, inside and out: how special interest groups influence policy choices. Disponível em: $<$ http://www.lse.ac.uk/government/research/resgroups/PSPE/Working-papers/StephaneWolton-Lobbying-Inside-and-Out-How-SIGs-Influence-Policy-Choices.pdf $>$. Acesso em: 22 abr. 2017.

WRIGHT, John R. Interest groups and Congress: lobbying, contributions and influence. Washington: Longman, 1995. 
WRIGHT, John R. Trade policy lobbying in the European Union: who captures whom? In: COEN, David; RICHARDSON, Jeremy (Eds.). Lobbying the European Union: institutions, actors, and issues. Oxford: Oxford University Press, 2011. p. 277-297. Disponível em: $<$ http://docenti.unimc.it/andrea.prontera/teaching/2016/15964/files/business-lobbying-inthe-european-union_chapter_8_reading_week_3>. Acesso em: 15 mar. 2017.

WUNDERLICH, Alexandre. Dos Crimes Contra a Administração Pública. In: REALE JÚNIOR, Miguel (Coord.). Código Penal comentado. São Paulo: Saraiva, 2017.

. Dos Crimes Contra a Administração Pública. In: REALE JÚNIOR, Miguel (Org.). Direito penal: jurisprudência em debate. Rio de Janeiro: GZ, 2013. v. 4.

ZEIGLER, Harmon; BAER, Michael A. Lobbying: interaction and influence in American State legislature. Califórnia: Wadsworth Publishing Company, 1969.

ZETTER, Lionel. Lobbying: the art of political persuasion. London: Harriman House, 2014.

ZÜLCH, Henning; HOFFMANN, Sebastian. Lobbying on accounting standard setting in a parliamentary environment: a qualitative approach. Leipzig Graduate School of Management, Working Paper n. 94, Leipzig, July 2010. Disponível em: $<$ http:/www.hhl.de/fileadmin/texte/publikationen/arbeitspapiere/hhlap0094.pdf $>$. Acesso em: 28 fev. 2017. 